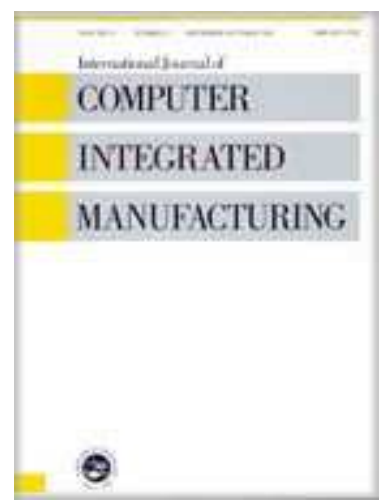

\title{
(Costing) An Integration Methodology for Automated Recurring Cost Prediction using Digital Manufacturing Technology
}

\begin{tabular}{|c|c|}
\hline Journal: & International Journal of Computer Integrated Manufacturing \\
\hline Manuscript ID: & TCIM-2010-IJCIM-0105 \\
\hline Manuscript Type: & Special Issue Paper \\
\hline $\begin{array}{l}\text { Date Submitted by the } \\
\text { Author: }\end{array}$ & 26-Jul-2010 \\
\hline Complete List of Authors: & $\begin{array}{l}\text { Jin, Yan; Queen's University Belfast, School of Mechanical and } \\
\text { Aerospace Engineering } \\
\text { Curran, Ricky } \\
\text { Burke, Robert } \\
\text { Welch, Brian }\end{array}$ \\
\hline Keywords: & $\begin{array}{l}\text { MANUFACTURING INFORMATION SYSTEMS, MANUFACTURING } \\
\text { ENGINEERING, COST MANAGEMENT, COSTING, INTEGRATION }\end{array}$ \\
\hline Keywords (user): & Digital manufacturing, knowledge \\
\hline
\end{tabular}

\section{SCHOLARONE ${ }^{\mathrm{m}}$ Manuscripts}




\title{
Special issue on costing in IJCIM.
}

Reference no. no number, handled by Dr Linda Newnes

Title: An Integration Methodology for Automated Recurring Cost Prediction using Digital Manufacturing Technology

\section{Authors:}

1. Yan Jin: (corresponding author) School of Mechanical \& Aerospace Engineering, Queen's University Belfast, UK BT9 5AH, email: y.jin@qub.ac.uk, Tel: +44 (0)2890974102

2. Ricky Curran: Faculty of Aerospace Engineering, Delft Univ. of Technology, 2629 HS Delft, The Netherlands, email: $\underline{\text { R.Curran@ } @ \text { tudelft.nl }}$

3. Robert Burke: Bombardier Aerospace Belfast, Airport Road, Belfast, UK BT3 9DZ, email: robert.burke@aero.bombardier.com

4. Brian Welch: Bombardier Aerospace Belfast, Airport Road, Belfast, UK BT3 9DZ, email: brian.welch@aero.bombardier.com

\begin{abstract}
:
The need to account for the effect of design decisions on manufacture and the impact of manufacturing cost on the life cycle cost of any product are well established. In this context, digital design and manufacturing solutions have to be further developed to facilitate and automate the integration of cost as one of the major driver in the product life cycle management. This paper is to present an integration methodology for implementing cost estimation capability within a digital manufacturing environment. A digital manufacturing structure of knowledge databases are set out and the ontology of assembly and part costing that is consistent with the structure is provided. Although the methodology is currently used for recurring cost prediction, it can be well applied to other functional developments, such as process planning. A prototype tool is developed to integrate both assembly time cost and parts manufacturing costs within the same digital environment. An industrial example is used to validate this approach.
\end{abstract}

Keywords: cost; manufacturing; digital; integration; knowledge 


\title{
An Integration Methodology for Automated Recurring Cost Prediction using Digital Manufacturing Technology
}

\author{
Y. Jin ${ }^{1}$, R. Curran ${ }^{2}$, R. Burke ${ }^{3}$ and B. Welch ${ }^{4}$ \\ ${ }^{1}$ School of Mechanical \& Aerospace Engineering, Queen's University Belfast, UK BT9 5AH \\ Email: y.jin@qub.ac.uk \\ ${ }^{2}$ Faculty of Aerospace Engineering, Delft Univ. of Technology, 2629 HS Delft, The \\ Netherlands \\ ${ }^{3,4}$ Bombardier Aerospace Belfast, Airport Road, Belfast, UK BT3 9DZ
}

\begin{abstract}
The need to account for the effect of design decisions on manufacture and the impact of manufacturing cost on the life cycle cost of any product are well established. In this context, digital design and manufacturing solutions have to be further developed to facilitate and automate the integration of cost as one of the major driver in the product life cycle management. This paper is to present an integration methodology for implementing cost estimation capability within a digital manufacturing environment. A digital manufacturing structure of knowledge databases are set out and the ontology of assembly and part costing that is consistent with the structure is provided. Although the methodology is currently used for recurring cost prediction, it can be well applied to other functional developments, such as process planning. A prototype tool is developed to integrate both assembly time cost and parts manufacturing costs within the same digital environment. An industrial example is used to validate this approach.
\end{abstract}

Keywords: cost; manufacturing; digital; integration; knowledge

\section{Introduction}

Modern manufacturing enterprises are facing unprecedented competitive pressure to improve productivity, migrate rework rate and make the right decision at first time, so as to reduce cost and shorten the time for their products on markets. It is estimated that about seventy percent of manufacturing cost is determined at the design stage, in which there is not enough production information available. Many research efforts have been put into bring manufacturing knowledge into design domain at the early design stage. Latest research shows that some DFMA tools which facilitate to make design decisions for manufacturing and assembly have been developed (Boothroyd et al. 2002, Curran et al. 2005, 2007a, Jin et al. 2008, 2009a, 2009b, Zha et al. 2001). But almost all of them are only pieces of the simulation or function modules, which have not been effectively integrated into a comprehensive digital manufacturing environment which covers the whole product life cycle. More and more manufacturing companies are resorting to 
digital manufacturing software to implement truly lean enterprises (Curran et al. 2007a, 207c, Dassault Systems 2002, Schmitt 2007).

Digital manufacturing is defined as the ability to describe every aspect of the design-tomanufacturing process digitally - using tools that include digital design, CAD, office documents, PLM systems, analysis software, simulation, CAM software and so on (CIMdata 2006, DaltonTaggart 2007). Digital manufacturing is an emerging software technology that will become a fundamental and liberating component of product lifecycle management (Curran et al. 2007b). It provides a concurrent engineering platform for integrated product teams to achieve optimal product life cycle solutions. However, such tools cannot be embedded blindly and they often need to be company-specific, which poses new challenges on knowledge capture, date definition and transformation, and the development of effective and efficient decision making tools (Freedman 1999, Seino et al. 2001). Digital manufacturing solutions have to be applied within a framework of carefully developed and deployed closed-loop processes for both manufacturing planning and information management.

The work in this paper focuses on the integration method for cost estimation capability, which is part of a big project for implementing lean enterprises through digital manufacturing. This paper considers the development of a digital design and manufacturing modeling platform with integrated cost analysis capabilities, providing a truly collaborative methodology and concurrent engineering tool for shortening aircraft assembly time, so as to reduce aircraft life cycle cost. A digital manufacturing framework is analyzed and requirements of developing assembly cost estimating functionalities within it are addressed. A digital manufacturing structure of knowledge databases are set out and the ontology of assembly and part costing that is consistent with the structure is provided. This will help design, manufacturing and IT engineers 
to bridge their knowledge gap. A digital platform solution for implementing rapid and effective assembly cost assessment is addressed. The assembly cost is composed of two sections. One results from the assembly time costing, and another from parts manufacturing cost. A structure oriented method, supported by an expert system and standard time library, has been proposed for automated time analysis in our previous paper (Jin et al. 2009a). This paper will provide general guidelines for function developments and integration methodology with a digital manufacturing platform. Techniques for implementing parts costing and the integration methodology will also be introduced.

This paper consists of six sections. Section 2 reviews literatures. Section 3 addresses digital manufacturing frameworks and its development requirements. Sections 4 and 5 introduce the integration methodology and application, respectively. Section 6 presents validation through a case study, and Section 7 concludes the paper.

\section{Literature Review}

Cost metric are very important throughout design, planning and production. It is reported that around seventy percent of the manufacturing cost is determined at the design phase (Freedman 1999, Curran 2004). Many companies and researchers have put their great efforts on developing design for manufacturing/production tools by integrating cost metrics (Boothroyd et al. 2002, Curran et al. 2005, Brown 2000, Herrmann and Chincholkar 2000, Maropoulos 2003, Thannhuber et al. 2001, Grewal and Choi 2005). However, most of their works are only pieces of the simulations or function modules, which cannot cover the whole product life cycle, so that a comprehensive design environment is imperatively required. More and more manufacturing companies, such as Airbus, Boeing and Bombardier, have recently started utilizing digital design and manufacturing tools to implement truly lean enterprises (Curran et al. 2007a, Butterfield et 
al. 2007, Herrmann and Chincholkar 2000, Maropoulos 2003). And many researcher groups are currently looking at developing a more integrated approach to design and digital manufacturing (Curran et al. 2007a, Butterfield et al. 2007, Freedman 1999, Maropoulos 2003). Freedman (1999) compared the engineering process of traditional "physical" engineering and modern virtual engineering, and discussed the benefits of digital manufacturing, such as collaborative engineering and simulation based design resulting in significant cost/time reduction. He also mentioned the challenges of implementing a fully digital enterprise, including the establishment and management of product, process and resource knowledge base across the whole enterprise. Curran et al. (2007a) proposed a concurrent approach for integrating cost capabilities into digital design and manufacturing modeling at the conceptual design phase. This approach offers the user to readily exploit the digital manufacturing simulation capabilities to get optimal solutions within the context of the whole aircraft life cycle cost. However, the implementation techniques have not been introduced yet, such as knowledge capture, transfer and storage. Scanlan et al. (2002) introduced a cost estimation tool using multi-level-abstraction models in support of preliminary design of aero structures, especially for an emerging design from initial conceptual phase to detail design phase. This tool makes use of an object-oriented data structure to capture design and manufacturing attributes and to ease the costing functionality development. Three levels are classified in terms of depth of product definition, so that suitable cost estimating models, i.e. parametric model for the initial high level conceptual design, generative model for the bottom level with all design and process details, and hybrid model in between, can be utilized respectively. Weustink et al. (2000) presented a generic framework for cost estimation and control for product design. The framework is constructed by basis elements associated with all cost attributes, including geometry, material, processes and production planning. The costs can 
be determined at different aggregation level by adding up the values of the cost attribute of every corresponding element. Zheng et al. (2008) introduced a six-level hierarchical model to facilitate systematic knowledge implementation, so as to generate process plans rapidly and effectively. By using this model, a variety of process knowledge at different granularity level can be easily managed and reused for developing process plans for new products. Huang et al. (2008) introduced a systematic methodology by integrating the Quality Function Deployment and Design Structure Matrix for product design planning to satisfy quality, scheduling and costing requirements. A framework, supported by a knowledge-based database is developed for implementing the methodology. The capability has been validated through a practical example. Elgh and Cederfeldt (2007) introduced a system engineering approach for the development of a tool to facilitate the concurrent producibility studies of products. Both the system level development and detailed functionalities for supporting the product development are addressed. Yan et al. (2001) developed a knowledge based computer aided tool for early design synthesis. A decision-making model is embedded in this tool to facilitate the designer's decision commitment for evolving design solutions. In the mean time, the casual relationships between the design decision and its consequent effects on manufacturing and assembly can be foreseen by the designer so as to justify his decision. Maropoulos et al. (2007) discussed the major problem in a large and complex product design and integration, i.e. design is separated from the manufacturing and assembly planning \& control within an enterprise. The aggregate process planning method and large-scale laser metrology approach was introduced for collaborative design and production engineering under a digital enterprise framework. Butterfield et al. (2007) investigated the benefits of using digital manufacturing tools by a case study on the assembly process optimization of aircraft fuselage. It clearly shows that digital manufacturing can bring 
many advantages, such as accelerating process and production planning, providing prerecorded simulations for operation training, reducing the number of design iterations. It also admits that various functional modules and tools are urgently required to be customized and developed for a unique company. This requires much collaboration between IT engineers, manufacturing engineers, and university researchers. In summary, knowledge and intelligence has become the key challenges to evolve the manufacturing enterprises to modern lean enterprise, which requires an effective, rapid and accurate cost assessment throughout the whole product life cycle (Thannhuber et al. 2001). This paper will propose a generic methodology for developing knowledge and intelligence within a digital manufacturing environment.

\section{Digital Manufacturing Framework}

More and more enterprises start using DM PLM software to lead their competitive advantage. However, they are often meeting the challenges of making use of the full potential of DM platform. In addition, most of them do not have enough resource and knowledge to develop their company-specific functionalities, which is key to the successful usage of a DM platform. Therefore, understanding DM framework and identifying requirements for to-be-developed functionalities are always the first step to achieve modern digital enterprises. 


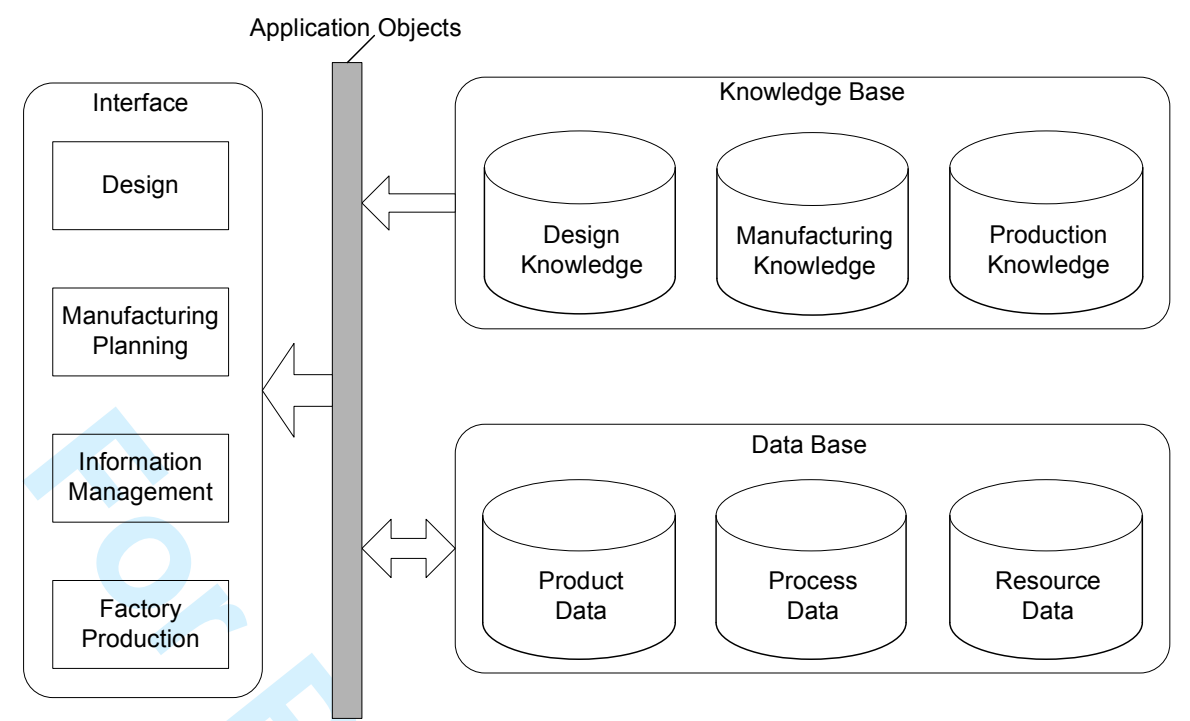

Fig.1 Architecture for a modern digital manufacturing system

Figure 1 shows a generic digital manufacturing framework for modern manufacturing enterprises. The framework holds a three-layer structure, i.e. interface layer, application objects layer, and background layer with knowledge base and data base. Application objects instances provide the carriers for all data and functionalities. Various digital tools are implemented through effective organization of these application objects instances. Each object has its attributes which represent object features, and its behaviours which use to manipulate attributes for certain functions, as shown in Fig. 2. This is the basis element. The data stored in database are the attributes values associated with every object instance. In a digital manufacturing environment, application objects are generally divided into three domains, i.e. product domain, process domain, and resource domain. Each domain normally holds a hierarchical architecture to map the inherent break-down feature of product, process and resource (PPR). For instance, a product is often composed by several sub-assemblies, and each sub-assembly consists of a number of parts/components. 


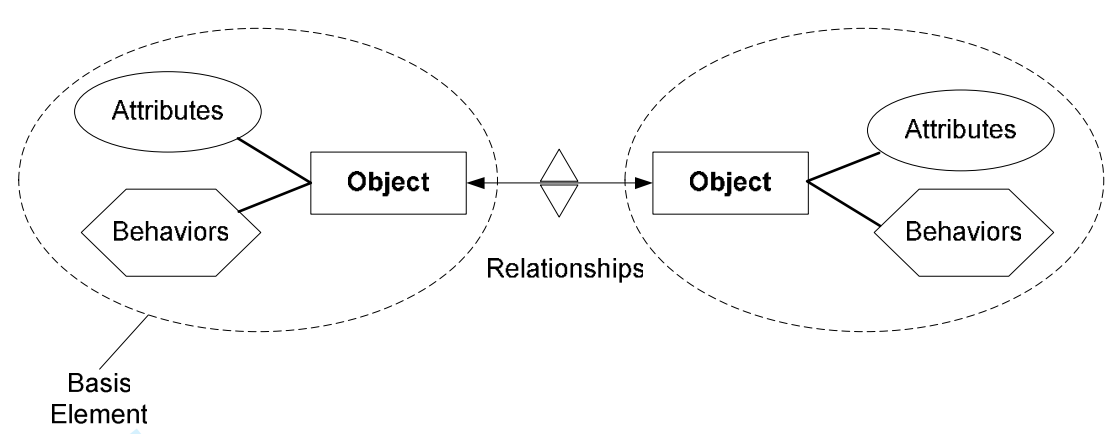

Fig. 2 Fundamental structure of a digital manufacturing software

Database is used to store attributes values of objects and is shared by all functional divisions for realize concurrent engineering, such as design, manufacturing and IT. Designers can utilize the existing manufacturing data to guide their design, while manufacturing engineers can read the CAD files directly for planning. With all data storing in the databases, more important is how to manipulate these data with user-friendly interfaces and implementing various digital functionalities. Existing commercial software, such as Delmia Digital Process Engineer, provides digital manufacturing platforms with a generic and open architecture with common functionalities, such as building up a product tree. However, some functionalities need to be company specific, and the corresponding interfaces need to be customized with particular requirements with the capability to save and retrieve data effectively and efficiently.

To fully take the advantages of digital manufacturing platforms, knowledge bases are urgently required. Intelligence has become the necessary symbol of a modern lean enterprise, as it helps companies realize their maximal productivity and make fully use of the digital manufacturing platform while reduce the error-prone manual process to minimum. Although each company like to have the intelligence, how to create and integrate intelligence in their system platform has become a big challenge. In essence, intelligence is often implemented through effective reasoning by inference engines linked with knowledge rules. To model these 
knowledge rules is to find out the casual relationships between design, manufacturing and resource data, i.e. object attributes. Three levels of relationships between attributes are to be modelled as follows.

- In one object: Relationships in between two or more attributes of one common object, such that volume and material density of a part will determine its weight.

- In one domain: Relationships of two attributes in the same domain, e.g. the material cost of an assembly will result from material costs of all its components/parts, while both the assembly object and component/part object belong to the product domain.

- Cross domain: Relationships in between two attributes of two objects respectively, such that size of a part will determine the time of its manufacturing operation, because a part lies in the product domain while an operation stays in the process domain.

This paper is to provide automated and intelligent cost estimating capability for aircraft assembly in a digital environment. The method used to achieve this will be to couple digital engineering capabilities with manufacturing cost estimating models. Generally speaking, the development will include cost breakdown analysis to identify required objects associated with attributes and behaviors, knowledge modeling for intelligent reasoning from EBOM (engineering bill of materials) to MBOM (manufacturing bill of materials), and seamless integration on the DPE platform.

\section{Methodology}

The recurring cost is resulted from two aspects, i.e. assembly time cost and parts manufacturing cost. The implementation methodology of these two will be addressed in this section. 


\subsection{Automated Assembly Time Costing}

\subsubsection{Time analysis and objects modelling}

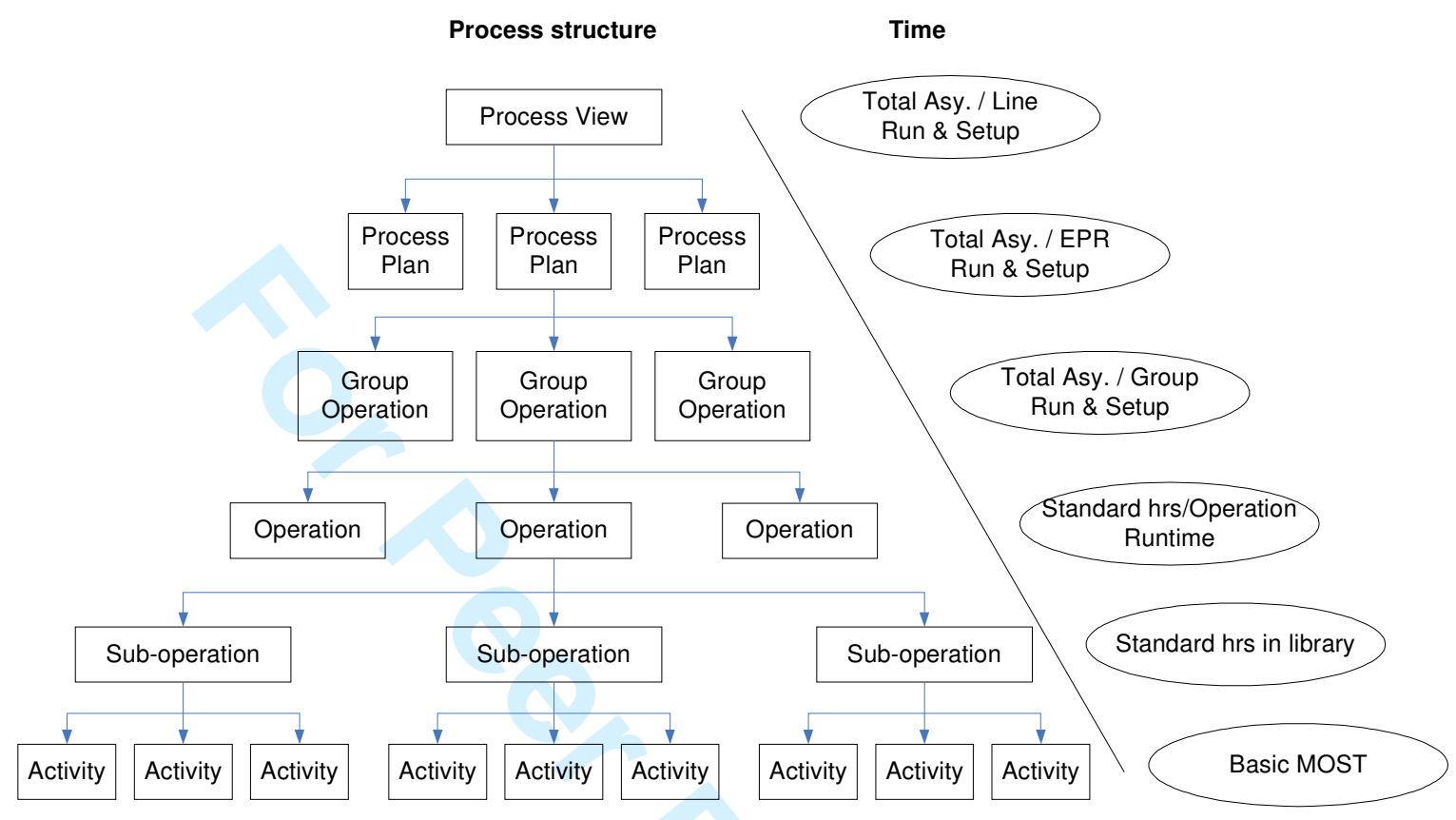

Fig. 3 Architecture of work breakdown structure utilized in time analysis

In order to facilitate the automatic generation of assembly times for different levels mapped to the different production phases, a suitable architecture is required to support effective information management and functionality development. This allows all required information to be efficiently and effectively captured, utilized and manipulated. The architecture must be able to capture all assembly breakdown information and time consumption procedure for producing the assembly. Based on shop floor practices, an object oriented hierarchical architecture is proposed to capture all assembly breakdown information and time consumption procedure for produce the assembly, as shown in Fig. 2. The architecture follows a top-down approach where each parent object is composed of several child objects in the level below. Such an architecture or template will facilitate both the process planning and the time generation explained below. The lowest level of this architecture is the human activity associated with MOST (Maynard Operation Sequence Technique) motions and with their associated standard times. MOST provides models 
for time measurements of manual operations based on pre-determined time standards associated with human activity. As the speed of MOST is far from sufficient to compute every time standard economically on a direct basis, a level of sub-operation, which is built up by the activities, is required. The operation level is defined by the type of assembly operation and relates to the basic ergonomic operations carried out on the shop floor. These basic elements that are referred to in the work instructions are equated to operational objects. These become the basic units for process planning, where generally only the runtime is associated with each operation. Subsequently, sequential operations are designated as forming a group-operation, with the setup time being input at this level. Each process plan consists of a sequence of groupoperations with an associated setup time; relating to the time taken to prepare tooling, etc. and review instructional materials. Similarly, a sequence of process plans make up a process view, where the setup time for building workstations will be taken into account. Finally, at each level a network needs be built up for the next higher-level assembly. As the operation time is related to the part attributes, such as size, weight and materials, the Part object associated with its attributes need to be modeled and linked to the Operation object. Based on the above analysis, the necessary attributes and behaviors are modeled as shown in Fig. 4. These objects are linked together by following the time generation logic. For example, the 'Get associate part' of the Operation object is to get the corresponding part ID so that the part attributes can be retrieved. The 'Populating times' is to trigger the expert system to populate Run time and Setup time attributes through a heuristic method, and 'Calculate cycle time' of Group_Operation object is used to roll up cycle times of all children operations in this group plus related setup time and time allowance. Other functionalities have also been developed for each object, such as output 
report and integrate learning curve for "Process Plan" objects. Please refer to (Jin et al. 2008) for details.
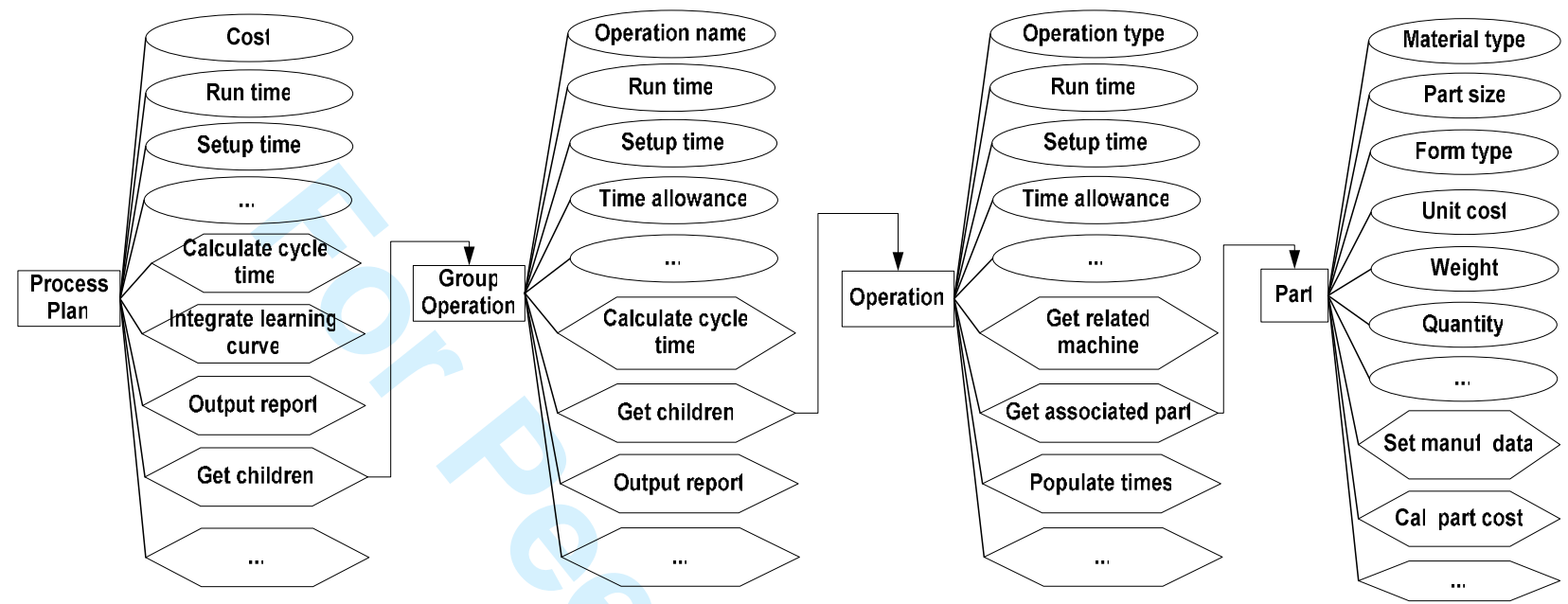

Fig. 4 Attributes and behaviors of objects for time estimating

\subsubsection{Knowledge modelling}

For implementing intelligent estimation of assembly time, two types of knowledge rules have been modelled as follows.

- In one domain: the relationship in between Operation, Group_Operation and Process_Plan objects. All setup times and roll-up algorithms in each level of the process architecture need to be modelled, e.g. if multiple "Drill" Operations take place in one Group_Opertion, then only one "Drill" setup time will be taken into account.

- Cross domain: the relationship between the Operation object and Part object, i.e. the mapping from EBOM to MBOM. For instance, if operation type is 'Locate', then the operation time can be determined by the part materials, size and weight, supported by the standard time library.

Various knowledge rules have been developed based on shop floor observations and engineers' interviews, please refer to (Jin et al. 2009) for more details. All these knowledge rules are stored in the knowledge base, and the inference engine can be triggered by the corresponding object behaviors as shown in Fig. 4. In a digital manufacturing environment, these object behaviors can be started by simply clicking a context menu or a command button. 


\subsubsection{Implementation methodology}

Figure 5 shows the implementation methodology for time estimation of a process plan. A standard time library is set up to store all sub-operations associated with standard process times, and a knowledge database is also build up to support the intelligent reasoning for automated time generation. All related data will be accessed to/from product and process database through application objects by the GUIs, as shown in Fig.1. The functionality of time prediction is started from the Operation level, i.e. populate the standard times for each operation instances. After triggering the 'Populate_times' behavior of each operation, the associated part attributes will be retrieved automatically to refine the related process type by expert system reasoning, so that standard times in the library can be located. Then the operation runtime and setup time will be resulted from quantity and standard times based on the customized algorithm. Once the time attributes of all operations are obtained, the time attributes values for each Group_Operation instance will then be calculated by all its children's times based on the process network, combining with the associated setup time, through the developed algorithm in this level. Similarly, the time attributes for next higher level, Process_Plan in this case, can be easily obtained. As the process architecture is extendable, the methodology can also be expanded to accommodate more levels in the hierarchy.

\subsection{Automated Part Costing}

\subsubsection{Attributes analysis and objects modelling}

Attributes analysis is referred to as the process of capturing all required attributes for implementing part costing, classifying these attributes into different domain, and finding out their ownerships in each domain so as to configure attributes associated with corresponding 
objects. If the attributes are common feature for all objects in one domain, the attributes should be created in the base class so that it can be inherited by all child class objects.

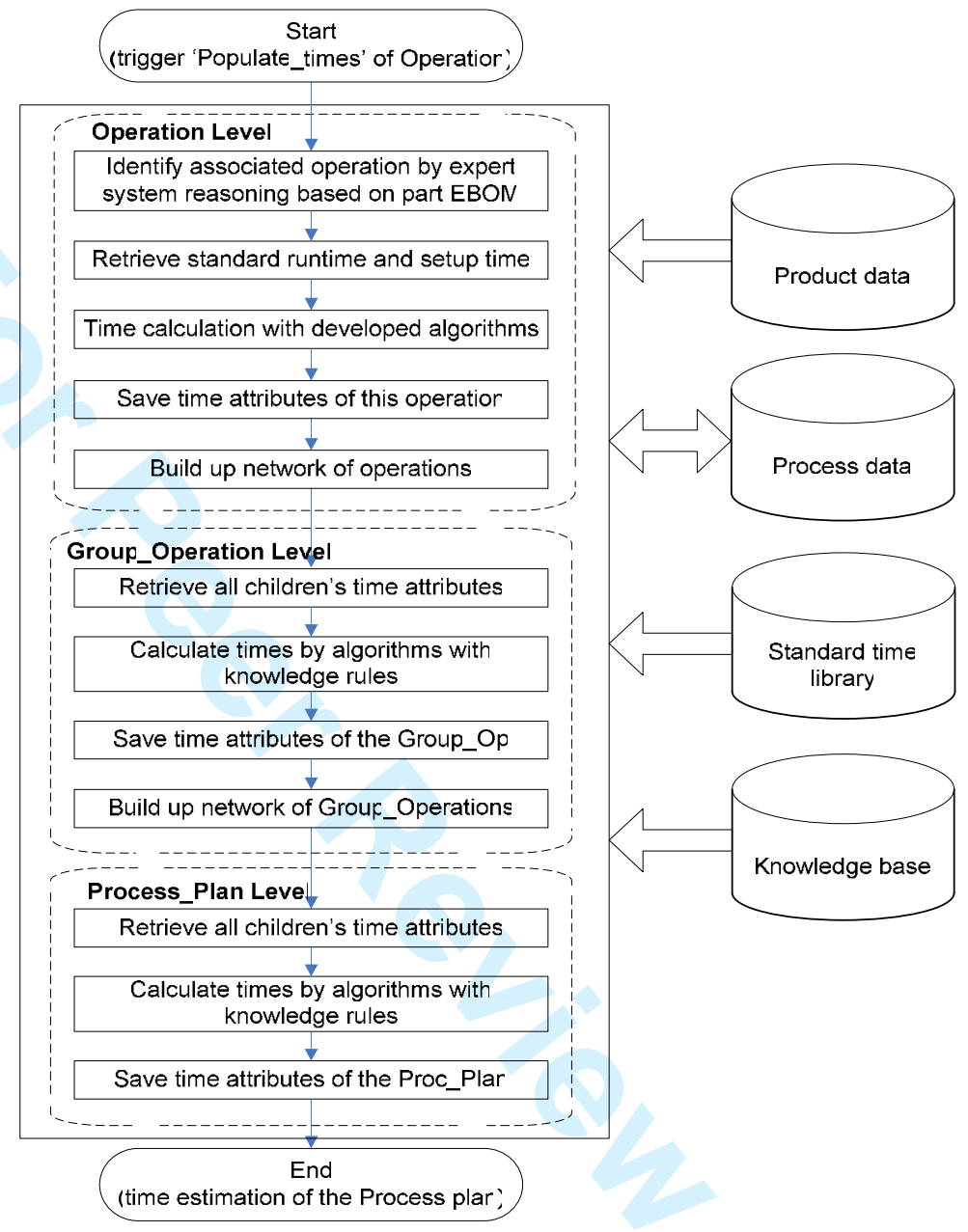

Fig. 5 Intelligent time prediction for operation object instances

Implementing part costing requires three types of information: (1) product information such as part raw material size, part finished size, material, and material cost; (2) process/production information, such as operation type, operation time, production quantity, learning curve, etc.; (3) resource information, such as machine cost, tooling amortization quantity, and labour rate. Figure 6 shows samples of the required objects and associated attributes. Obviously, part cost should be an attribute of 'Part' object and functionalities for setting or retrieve required attributes values and calculating cost using cost models should be 
created for 'Part' object. Attributes of machines and tools need to be created to construct the manufacturing process. All these information will be stored as attributes associated with corresponding objects in database. Clearly, finding out the casual relationships between these objects attributes is a cumbersome task of knowledge capturing, and is generally company specific. Gilmore (2008) presented a categorization hierarchy for manufacturing process selection with given early design information, such as part length, width, thickness and material type. The first level is the high level 'manufacturing Centre', which houses a number of similar processes that are linked due to similarity in function. In each manufacturing centre, categorization will be further refined by part material type, material form, size and capability and part family based on the process steps and available machines. This categorization hierarchy can be modelled into our digital manufacturing system as knowledge rules, so that the casual relationships between part attributes and machine, process and tooling attributes can be automatically related. Thus, the intelligence will be obtained. Some exemplar knowledge rules are listed as follows.

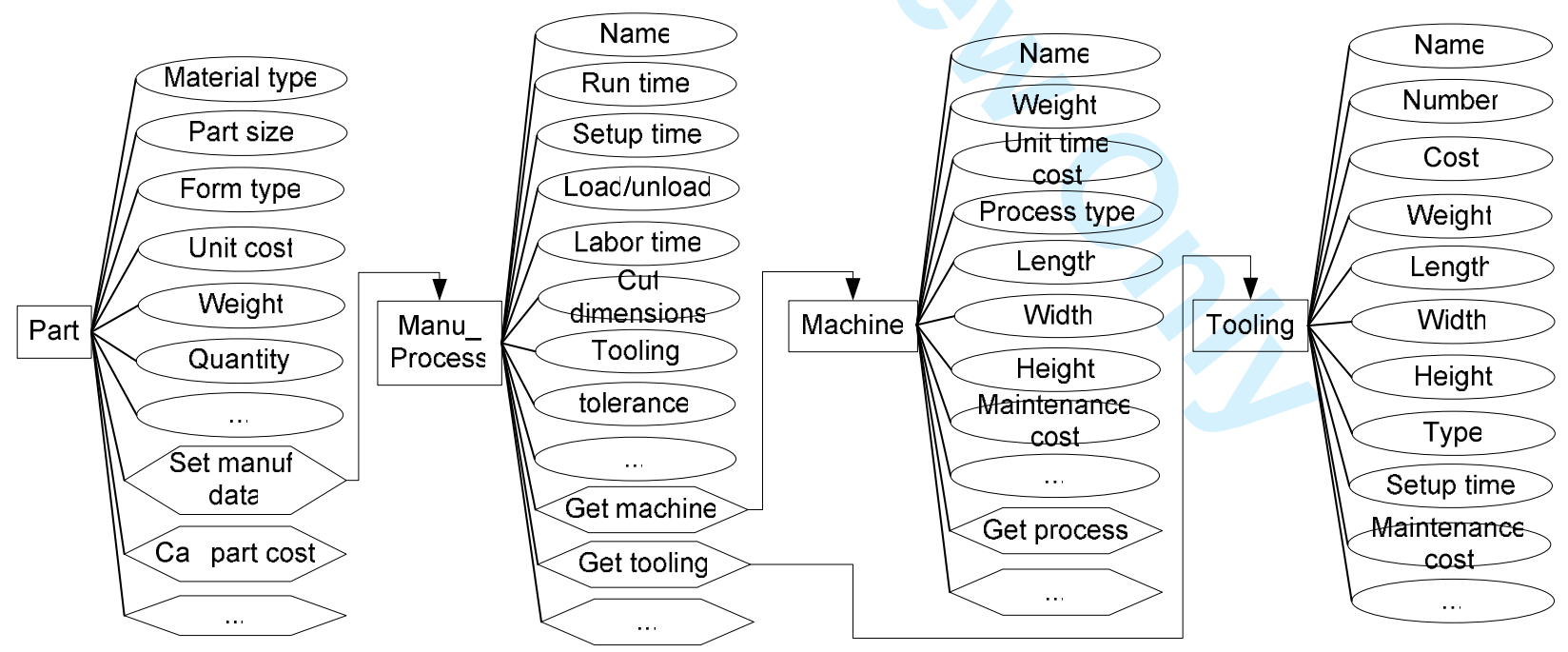

Fig. 6 Required objects and associated attributes for part costing 
If Part.Formtype $=$ 'Sheet ' \& Materialtype $=$ 'Alloy' or 'Titanium' or 'Steel' then MachiningCenter $=$ 'Sheet Metal Manufacturing Centre'

End if

If Part.Shape $=$ 'FlatRectangular' then

Part.BlankLength $=$ round $($ Part.Length +2.5$)$

Part. BlankWidth $=$ round $($ Part. Width +2.5$)$

Part.BlankThickness $=$ Part.Thickness

End if

$\cdots$

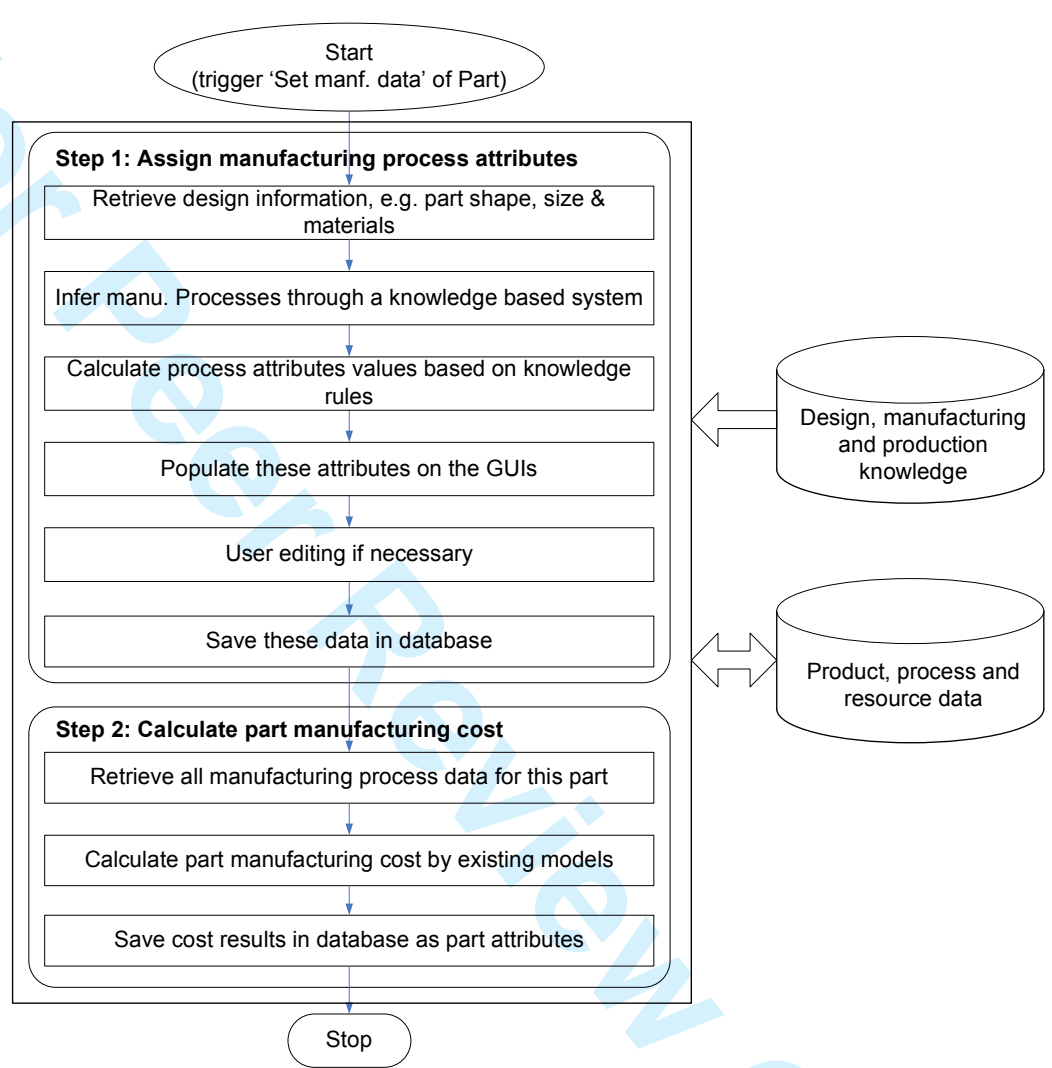

Fig. 7 Intelligent prediction of part manufacturing cost

\subsubsection{Implementation methodology}

Predicting part manufacturing cost requires two main steps as shown in Fig. 7. Step 1 is to generate or assign all manufacturing processes attributes. By triggering the behaviour of 'Set manufacturing data' of the Part object, the part design attributes will be automatically retrieved, so that the manufacturing processes and associated attributes can be intelligently inferred through knowledge based reasoning. Ideally, all these attributes should be automatically generated by retrieving relevant design manufacturing and resource information with support from knowledge 
systems. Even though some interactions with user may be indispensible, the interaction should be minimised. Once all these attributes values are obtained, they will be saved in the databases through application objects. The second step is to calculate part manufacturing cost with cost models by using these attributes values obtained in Step 1. The cost results will be saved as part attributes in the database.

\section{Application}

One popular software tool to realize digital manufacturing is Delmia Process Engineer (DPE), which helps process planning by integrating product, process and resource (PPR) information from the conceptual design phase through to the process planning phase and on to the production phase. It utilizes an object-oriented PPR tree structure which is capable of modeling complete project planning structures and all logical relationships between the PPR data. It provides users an open architecture to create new objects associated with attributes and behaviors, which are linked to a central database. GUIs of each object can be customized by advanced users. Application program interfaces (APIs) are offered in DPE for create bespoke functions which will be associated with application objects. In this work, DPE V5R17 is employed. All objects associated with attributes and behaviors developed in Section 4 are configured in DPE through its configuration manager. The related GUIs of these objects are customized accordingly. Figures 8 and 9 show two exemplar GUIs of an Operation and a Part instances respectively. These behaviors of each object are modeled using VB scripts, and visualized through either a command button or a context menu as shown in Fig. 8 and Fig. 10. The standard time library and knowledge bases are currently developed in spreadsheets for ease of management. The existing functionality of building up a process network for each level is utilized directly in this work. For more details on time analysis, please refer to (Jin et al. 2009a). 


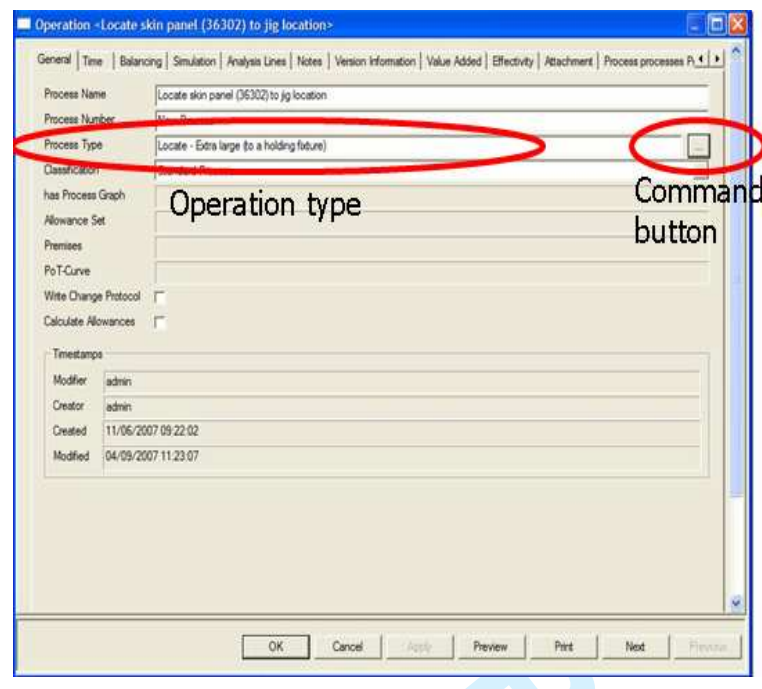

Fig. 8 Customized GUI of Operation object

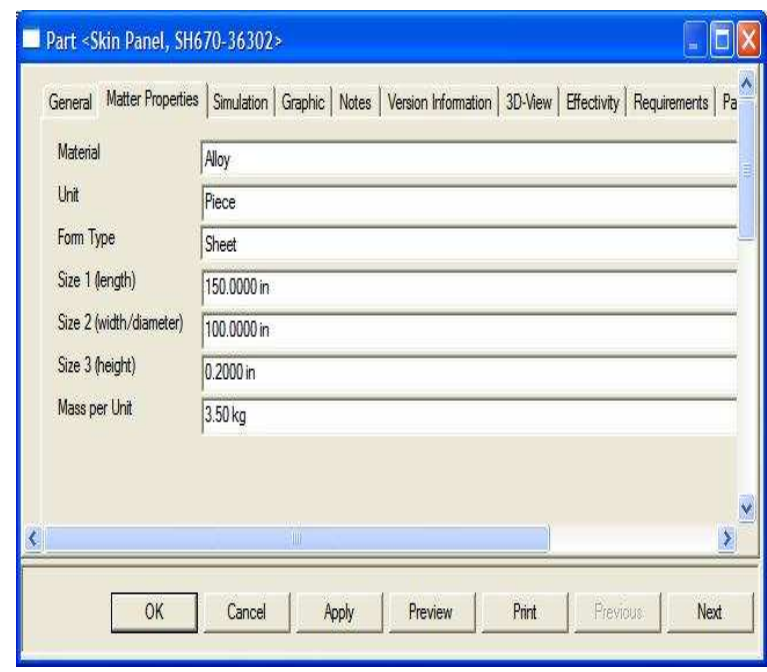

Fig. 9 Customized GUI of Part object

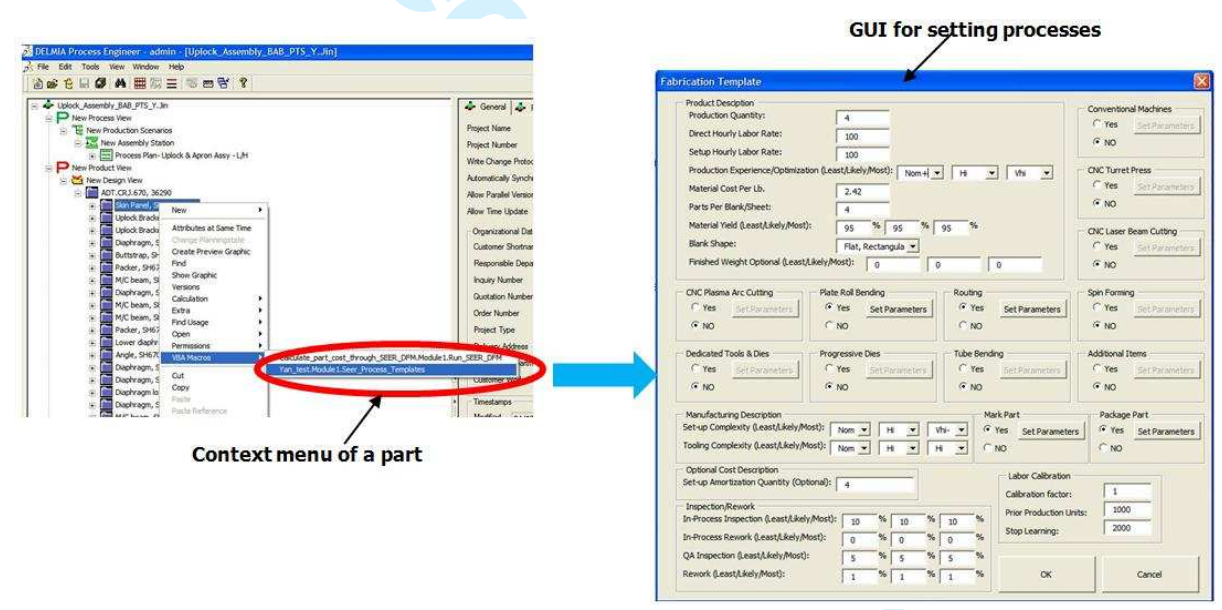

Fig. 10 Graphical user interfaces for part costing

To provide required data for part cost estimates, GUIs are created for users to visualize and edit these cost required attributes in DPE by VB scripts as shown in Fig. 10. For rapidly obtaining the capability of cost estimation for any components, SEER-DFM software is selected as the computation engine for calculating part cost. SEER-DFM is a commercial software, which provides cost estimation capability with parametric cost models based on manufacturing processes. To utilize SEER-DFM, the user generally needs to have expert manufacturing knowledge and manually input the required design and production information for accurate cost 
estimates. To avoid the tedious manual input process and make use of full potential of digital manufacturing, an automated data manipulation mechanism needs to be developed. This will involve a closed loop process in between DPE and SEER-DFM as shown in Fig. 11. Based on the attributes in DPE, the server mode scripts commands for SEER-DFM can be generated by our customized scripting program into a spreadsheet first. Then SEER-DFM will be automatically invoked to run through these commands to calculate the part costs, and save cost results in a spreadsheet, and send required cost results back to DPE in the end.

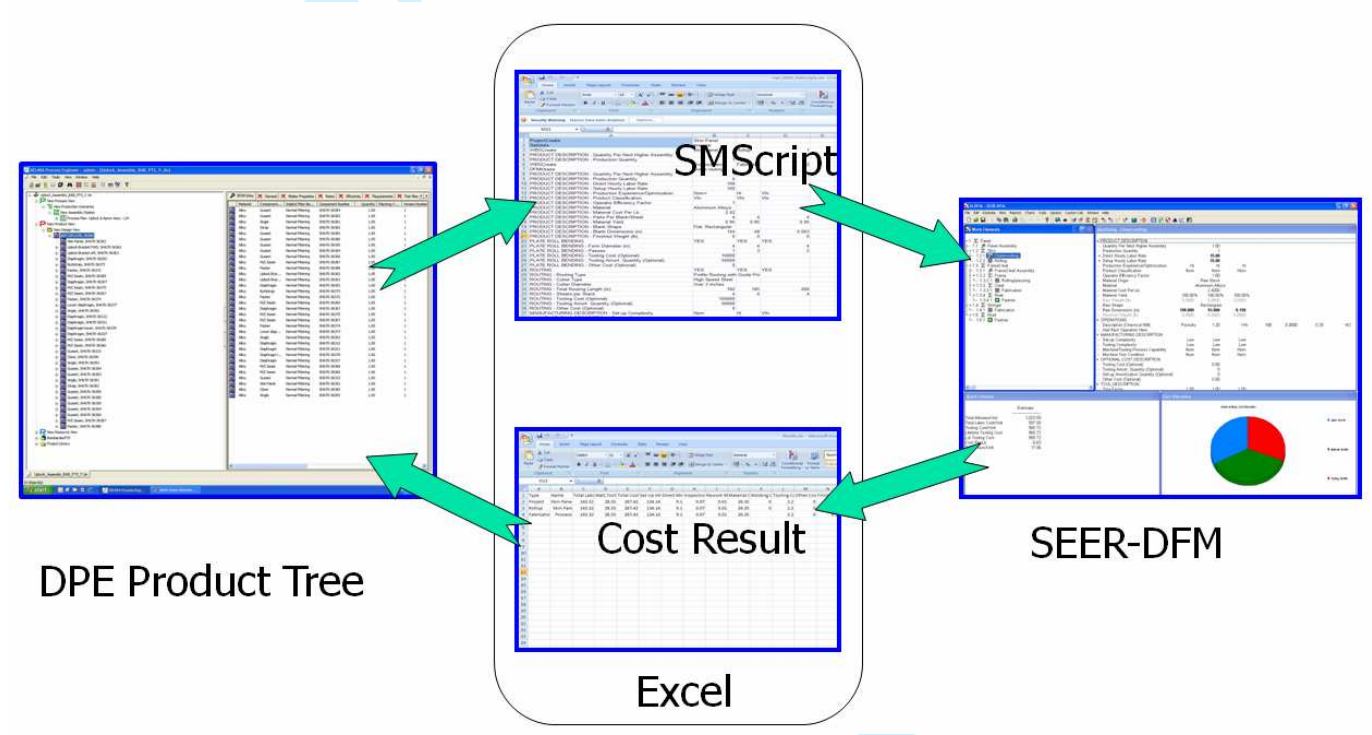

Fig. 11 Integration of DPE and SEER-DFM

To sum up both time cost and parts cost together, digital functionality is developed in DPE by using VB scripts. A context menu associated with "Process Plan" object is created for execute the function as shown in Fig. 12. To develop the algorithm to calculate the assembly cost, we need to be very careful to integrate the learning curve model into the assembly time costing and avoid repetitive costing for the same part, because one part may pass through multiple operations. Figure 13 shows the procedure of calculating assembly cost. To integrate the learning curve model correctly, the system will ask the user to input the total number sets of 
assemblies. And the time costing will be averaged by the total number of assemblies. To avoid repetitive summation of part cost, all related part IDs associated with all operations need to be retrieved and repetitive ones should be removed. As a result, the average time costing is summed with all parts costs to form the assembly cost in the output report.

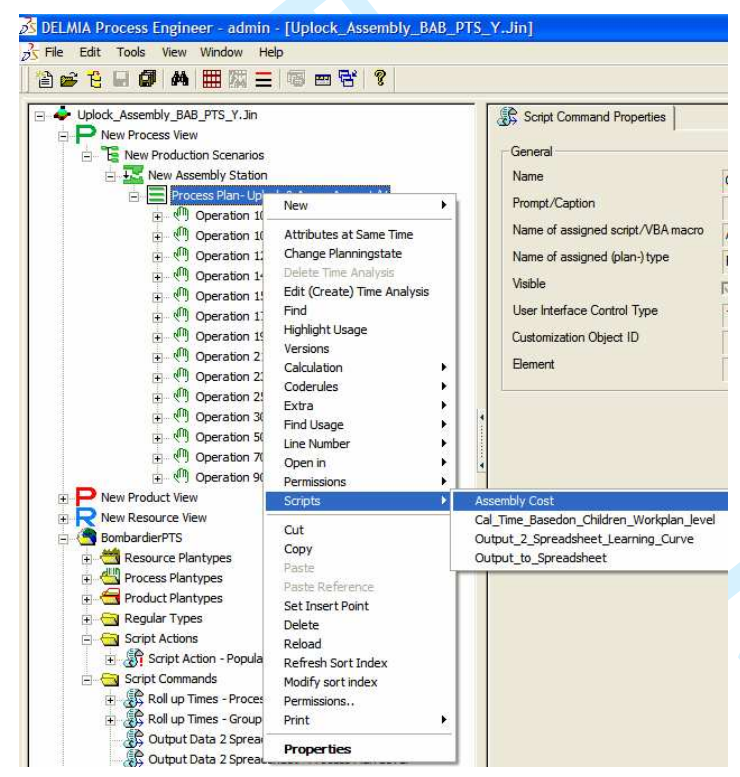

Fig. 12 Context menu for calculating assembly cost assembly cost

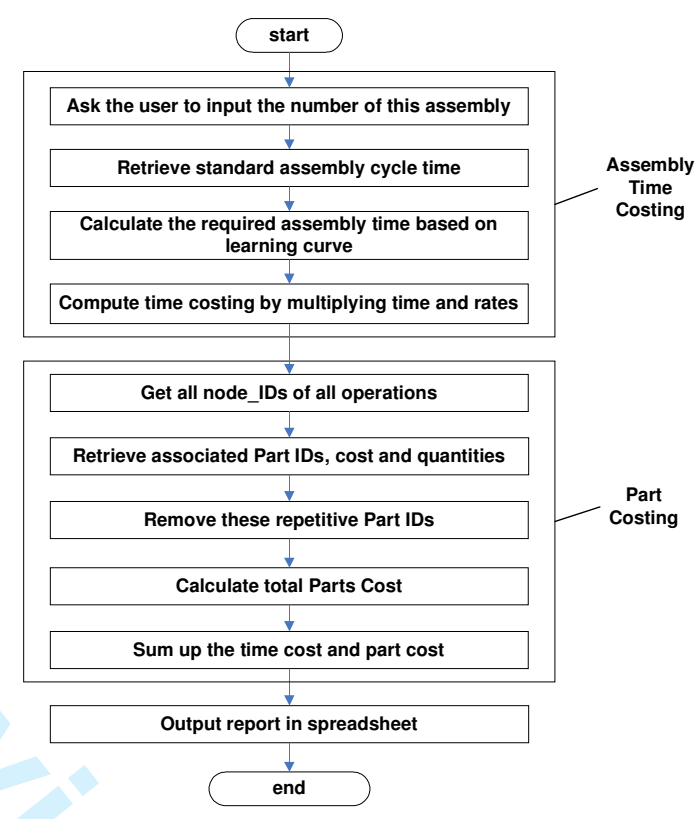

Fig. 13 Flowchart for calculating

\section{Validation}

An exemplar study is carried out using the Uplock \& Apron Assembly for one of Bombardier's current regional passenger jets as shown in Fig. 14. The original assembly book for this panel composed of 250 operations associated with 148 parts, is written by a process planner based on experience, without considering assembly time. Methods engineers then need to manually calculate the time for each operation based on the assembly book which contains twenty pages of text with drawing references but no graphical illustrations. This is a very time consuming and error prone process, and rework is often required on the assembly book due to the unbalanced 
line, where different modules have quite different times making it difficult to balance. Based on the proposed process structure mentioned before, the assembly book can be easily modeled, and the objects of different production level can be easily established as shown in Fig. 15. The assembly book maps to the process plan level, and the next lower level, such as Operation 10 and Operation 30, maps to the Group Operation level. Each Group Operations is consisted of a number of operations, such as "locate skin panel". These required functional modules on each level are implemented by VB scripts in Bombardier Aerospace in Belfast, UK.

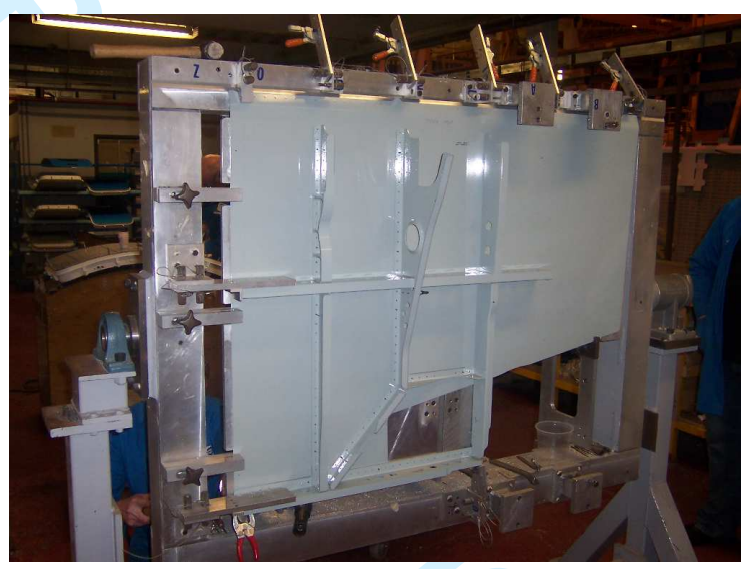

Fig. 14 Uplock and Apron Assembly (With Fixture)

Assembly time was calculated by rolling up operations run times as well as setup times based on the proposed architecture as shown in Fig. 3. Assembly time cost is a product of assembly time and labor rate. As the assembly time obtained is the optimal time by using the "best" methods, it maps to a bottom point on the learning curve after gaining a lot of experience from many times of repetitive work. Therefore, assembly time needs to be calibrated using learning curve to calculate its cost for a certain set of assembly. In our project, the average unit assembly time will be used to calculate unit cost for a set of repetitive assemblies. 


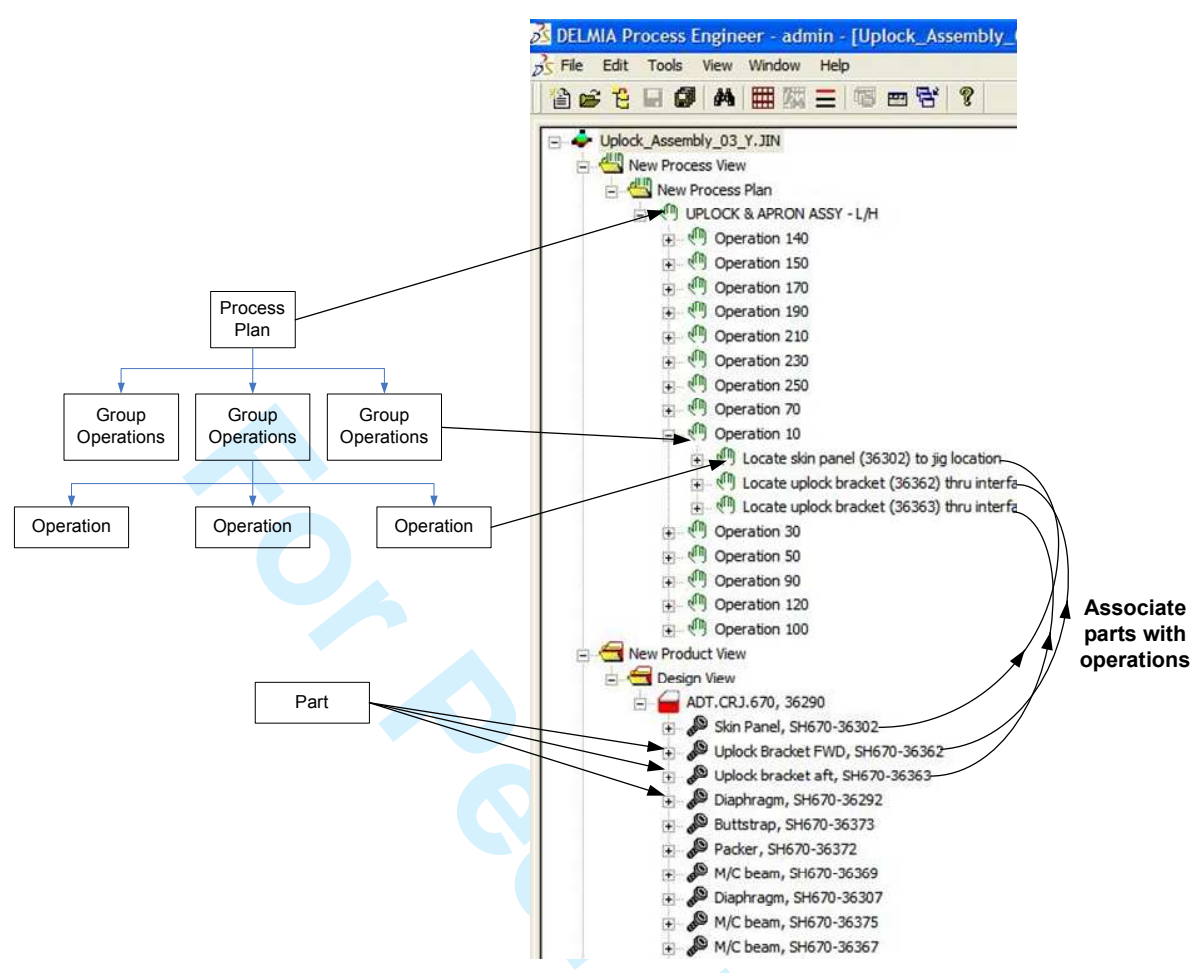

Fig. 15 Implementation of the object oriented process structure in DPE

For part costing, an exemplar part "Skin Panel", was used. The flat rectangular part is made of aluminum alloy, with the dimensions (in inches) $45.68 \times 35.246 \times 0.063$. The part is made by profile routing from an aluminum alloy sheet plate, followed by roll bending, and inprocess inspection and packaging. The size and material information can be directly retrieved from part CAD files, so that blank sheet form and blank size will be automatically set in the interface as shown in Fig. 11. The other attributes need be set manually at current stage, although the final objective is to transfer all data automatically.

Once all data are set, these data will be saved by clicking the OK button in Fig. 8. After clicking the context menu for linking SEER-DFM, Server Mode Scripts will be automatically generated at background, and SEER-DFM will be automatically triggered to run through all these scripts commands to compute part cost and save detailed cost estimates in a background sheet. Then the required results, unit cost in this case, is returned to DPE as an attribute of the 
part "Skin Panel". The user can also open the spreadsheets of the Server Mode scripts and detailed cost results for a double check later on. With all parts cost available, assembly cost can be calculated by summing up the time cost and all parts cost by clicking the context menu shown in Fig. 12. Both time cost and part cost will be list out in a spreadsheet as shown in Fig. 16. Note that the data here are normalized data for confidential reasons.

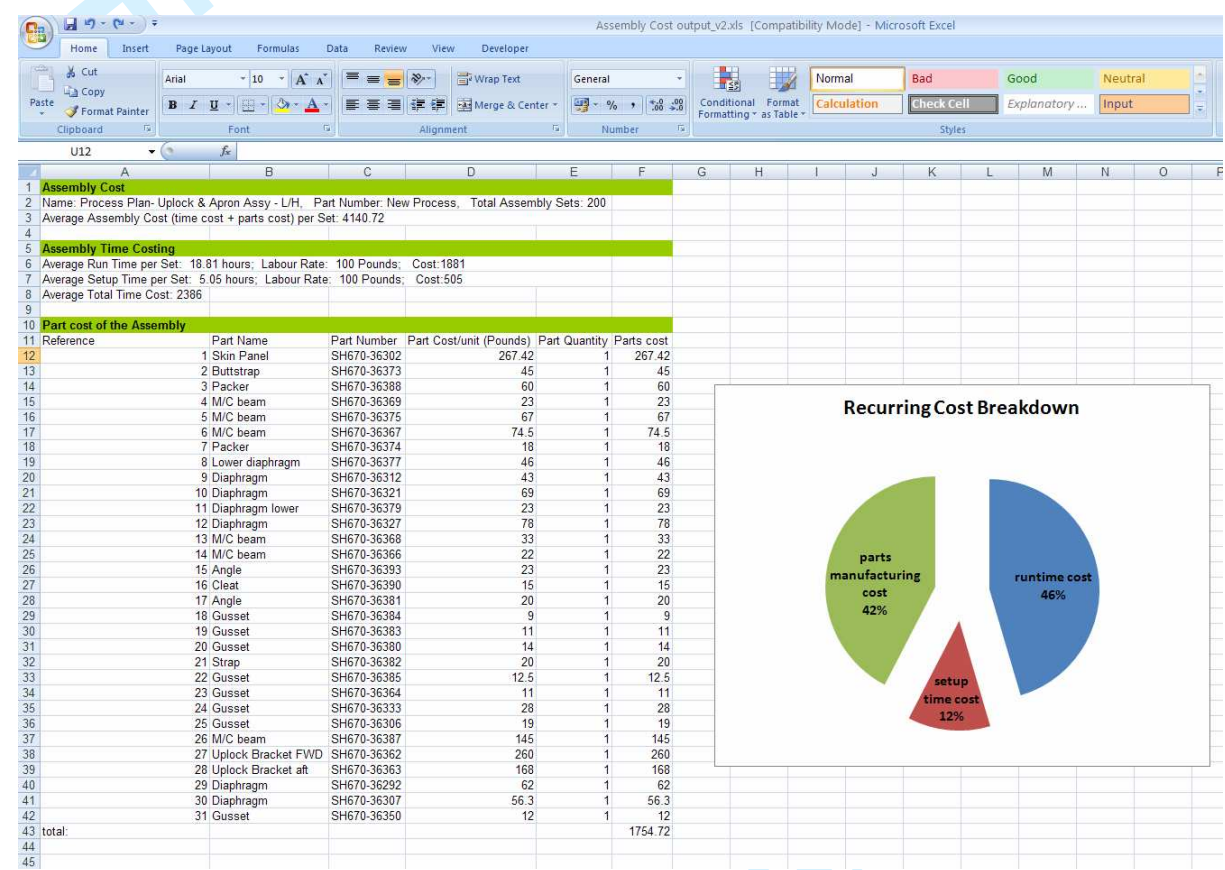

Fig. 16 Output report of assembly cost of the Uplock \& Apron Assembly

\section{Conclusion}

Although cost models have been studied in the last two decades and some software tools are available for cost analysis, the integration within a digital manufacturing environment is still out of literature. This paper addresses this issue and fills in the gap for developing a digital platform solution for rapid and effective cost assessment. A digital manufacturing structure of knowledge databases is set out, and the ontology of assembly and part costing consistent with the structure is proposed. A generic digital functionality development process is introduced to clear off the knowledge barrier in between engineering and IT. A methodology for implementing automated 
and intelligent cost estimation is presented. A prototype tool is developed to integrate both assembly time cost and parts costs within a digital environment. An industrial example is used to validate the method. This work helps to bridge the knowledge gap between design, manufacturing and IT engineers. It also provides guidelines for developing bespoke functionalities coupled with advanced digital manufacturing capabilities.

Acknowledgments

The authors gratefully acknowledge the help and guidance of Paul Smith, Gerry Mcgrattan, Donna Mcaleenan of Bombardier Belfast, Tom Edgar, Colm Higgins and Rory Collins of the Northern Ireland Technology Centre, William McEwan and Joseph Butterfield in School of Mechanical and Aerospace Engineering at Queen's University, and Jason Jones and Simon Allsop of DELMIA UK, without whom this work would not have been possible.

\section{References}

Boothroyd, G., Dewhurst, P., and Knight, W., 2002. Product Design for Manufacture and Assembly, Marcel Dekker Ltd. New York.

Brown, R.G., 2000. Driving Digital Manufacturing to Reality, Proceedings of the 2000 Winter Simulation Conference, Orlando, FL, USA, Dec. 2000, 224 - 228.

Butterfield, J., et al., 2007. Optimization of Aircraft Fuselage Assembly Process Using Digital Manufacturing. Journal of Computing and Information Science in Engineering, 7, 269-275.

CIMdata, 2006. The Value of Digital Manufacturing in a PLM Environment Case Study: Fiat Auto S.p.A. Available from:

http://www2.warwick.ac.uk/fac/sci/wmg/ftmsc/content_store/dmmsite/context/fiat_dig_mfg_benefits.pdf [Accessed 20 Sep. 2008].

Curran, R., Raghunathan, S., and Price, M., 2004. Review of Aerospace Engineering Cost Modeling: The Generic Causal Approach, Progress in Aerospace Science, 40, 487-534.

Curran, R., et al., 2005. Integrating Aircraft Cost Modeling into Conceptual Design. Concurrent Engineering: Research and Applications, 13 (4), 321-330.

Curran, R., et al., 2007a. Integrated digital design for manufacture for reduced life cycle cost. Int. J. Production Economics 109, 27-40.

Curran, R., et al., 2007b. Digital Design Synthesis and Virtual Lean Manufacture, $45^{\text {th }}$ AIAA Aerospace Sciences Meeting and Exhibition, Reno, Nevada, 8-11 Jan. 2007. 
Curran, R., et al., 2007c. Digital Lean Manufacture (DLM) for Competitive Advantage, 7th AIAA Aviation Technology, Integration and Operations Conference, 18 - 20 Sep., Belfast, Northern Ireland.

Dalton-Taggart, R., 2007, The move to digital manufacturing [online], Available from: http://www.manufacturingcenter.com/tooling/archives/0405/0405move_to_digital.asp [Accessed 10 Oct. 2007].

Dassault Systems Press Conferences, 2002. Delmia Solutions for the Airbus A380, Fellbach, Germany, $26^{\text {th }}$ Febrary.

Elgh, F., and Cederfeldt, M., 2007. Concurrent cost estimation as a tool for enhanced producibility-System development and applicability for producibility studies, International Journal of Production Economics, 109 (1-2), 12-26.

Freedman, S., 1999. An Overview of Fully Integrated Digital Manufacturing Technology, Proceedings of the 1999 Winter Simulation Conference, Squaw Peak, Phoenix, Dec. 1999, 281285.

Gilmour, M.W., 2008. Development of a Manufacturing Estimation Methodology for Early Aero-Structure Design, Thesis (PhD), Queen's University Belfast, UK.

Grewal, S., and Choi, C.K., 2005. An Integrated Approach to Manufacturing Process Design and Costing, Concurrent Engineering: Research and Applications, 13 (3), 199-207.

Herrmann, J. W., and Chincholkar, M. M., 2000. Design for production: a tool for reducing manufacturing cycle time, Proceedings of ASME Design Engineering Technical Conference, Baltimore, Maryland, Sep. 2000, $1-10$.

Hung, H.F., Kao, H.P., and Juang, Y.S., 2008. An integrated information system for product design planning, Expert Systems with Applications, 35 (1-2), 338-349.

Jin,Y., et al., 2008. Automated Assembly Time Analysis Using a Digital Knowledge Based Approach. The 26th Congress of International Council of the Aeronautical Sciences (ICAS) 14 19 September 2008, Anchorage, Alaska.

Jin,Y., et al., 2009a. Intelligent Assembly Time Analysis Using a Digital Knowledge Based Approach. Journal of Aerospace Computing, Information, and Communication, 6, 506-522.

Jin,Y., et al., 2009b. An Integration Methodology for Automated Recurring Cost Prediction using Digital Manufacturing Technology, International Conference of Manufacturing Research, Warwick, UK.

Maropoulos, P.G., 2003. Digital enterprise technology-defining perspectives and research priorities, Int. J. of computer integrated manufacturing, 16 (7-8), 467 - 478. 
Maropoulos, P.G., et al., 2007. Key digital enterprise technology methods for large volume metrology and assembly integration, Int. J. of Production Research, 45(7), 1539-1559.

Scanlan, J., et al., 2002. Cost modelling for aircraft design optimization, Journal of Engineering Design, 13(3), 261-269.

Schmitt, P., 2007. Boeing, Others Rely on Digital Manufacturing. Dassault Systems - Design News, $30^{\text {th }}$ April.

Seino, T., et al. 2001. The impact of 'digital manufacturing' on technology management, Portland International Conference on Management of Engineering and Technology, PICMET '01. Portland, 1, 31-32.

Thannhuber, M., Tseng, M.M., and Bullinger, H., 2001. An Autopoietic Approach for Building Knowledge Management Systems in Manufacturing Enterprises, Annals of the CIRP, 50(1), 313 $-318$.

Weustink, I.F., et al., 2000. A generic framework for cost estimation and cost control in product design, Journal of Materials Processing Tech., 103 (1), 141-148.

Yan, X.T., Borg, J.C., and Juster, N.P., 2001. Concurrent modelling of components and realization systems to support proactive design for manufacture/assembly. Proceedings of the Institution of Mechanical Engineers, Part B: Journal of Engineering Manufacture, 215 (8), 1135-1141.

Zha, X.F., Du, H.J., and Qiu, J.H., 2001. Knowledge-based approach and system for assembly oriented design, Part I: the approach. Engineering Applications of Artificial Intelligence 14, 6175 .

Zheng, L.Y., et al., 2008. Systematic modeling and reusing of process knowledge for rapid process configuration, Robotics and Computer Integrated Manufacturing. 24(6), 763-772. 
Fig.1 Architecture for a modern digital manufacturing system

Fig. 2 Fundamental structure of a digital manufacturing software

Fig. 3 Architecture of work breakdown structure utilized in time analysis

Fig. 4 Attributes and behaviors of objects for time estimating

Fig. 5 Intelligent time prediction for operation object instances

Fig. 6 Required objects and associated attributes for part costing

Fig. 7 Intelligent prediction of part manufacturing cost

Fig. 8 Customized GUI of Operation object

Fig. 9 Customized GUI of Part object

Fig. 10 Graphical user interfaces for part costing

Fig. 11 Integration of DPE and SEER-DFM

Fig. 12 Context menu for calculating assembly cost

Fig. 13 Flowchart for calculating assembly cost

Fig. 14 Uplock and Apron Assembly (With Fixture)

Fig. 15 Implementation of the object oriented process structure in DPE

Fig. 16 Output report of assembly cost of the Uplock \& Apron Assembly 


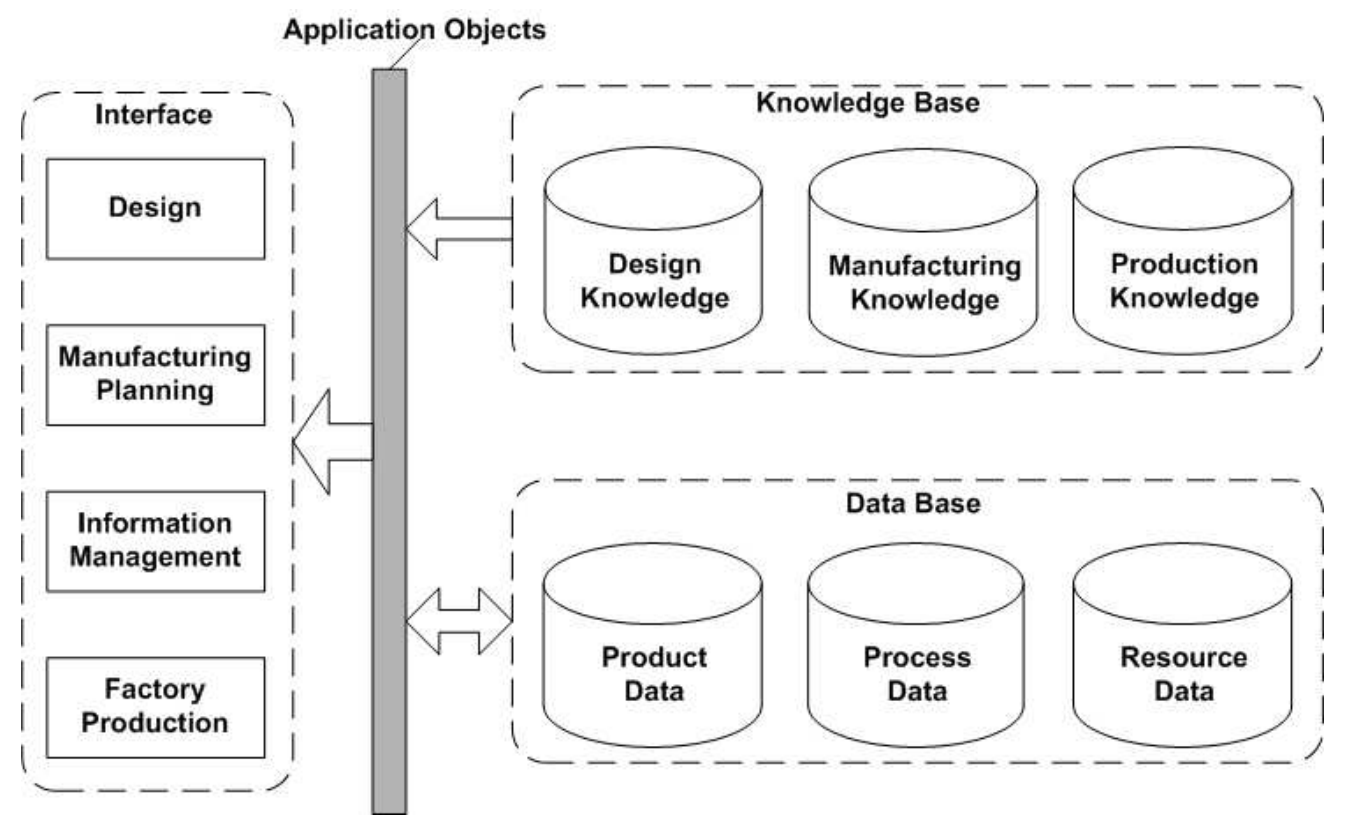

Architecture for a modern digital manufacturing system $196 \times 121 \mathrm{~mm}(96 \times 96 \mathrm{DPI})$ 


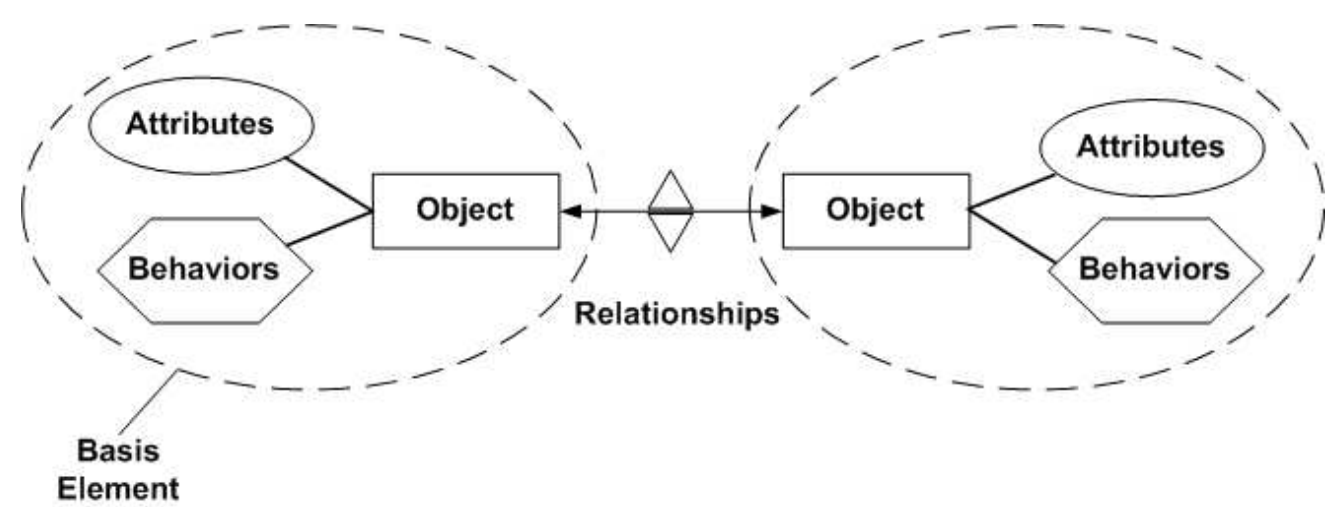

Fundamental structure of a digital manufacturing software $174 \times 65 \mathrm{~mm}(96 \times 96 \mathrm{DPI})$ 


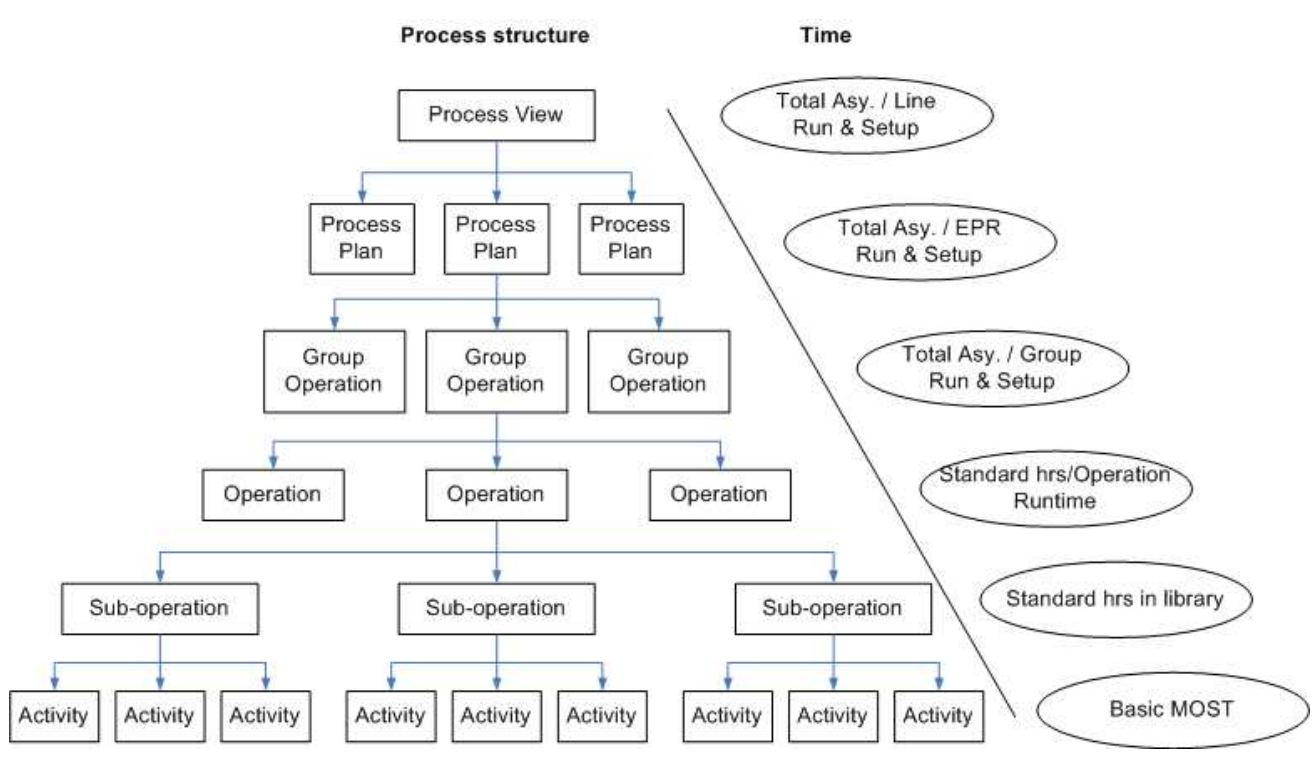

Architecture of work breakdown structure utilized in time analysis $205 \times 115 \mathrm{~mm}(96 \times 96$ DPI) 


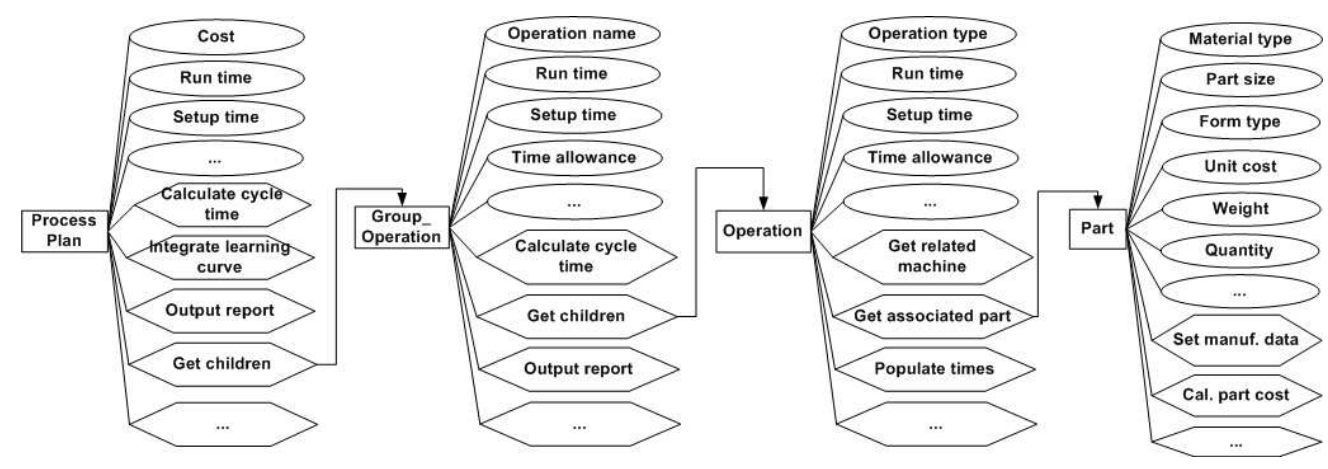

Attributes and behaviors of objects for time estimating $271 \times 91 \mathrm{~mm}(96 \times 96 \mathrm{DPI})$ 


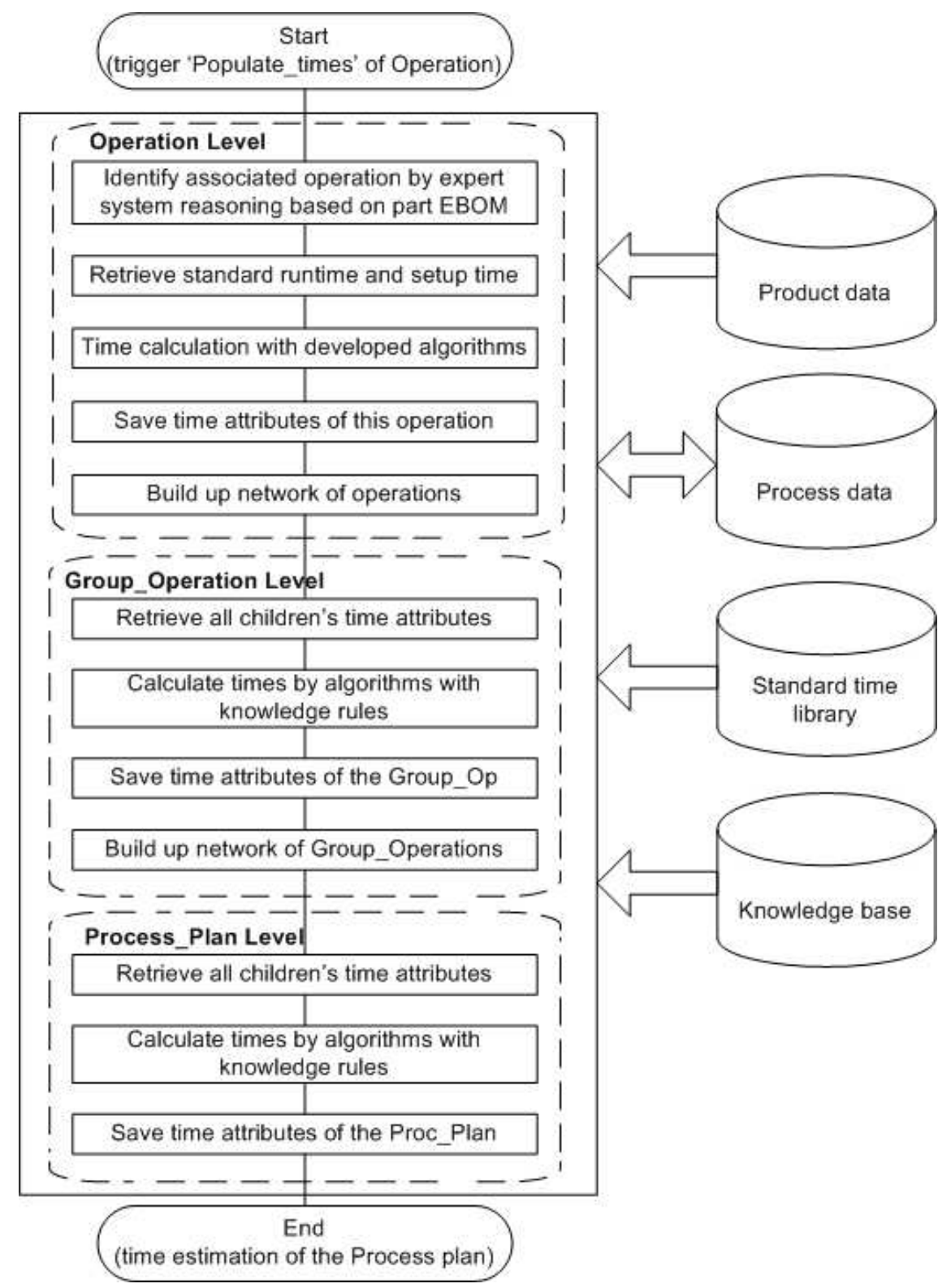

Intelligent time prediction for operation object instances $138 \times 191 \mathrm{~mm}(96 \times 96 \mathrm{DPI})$ 


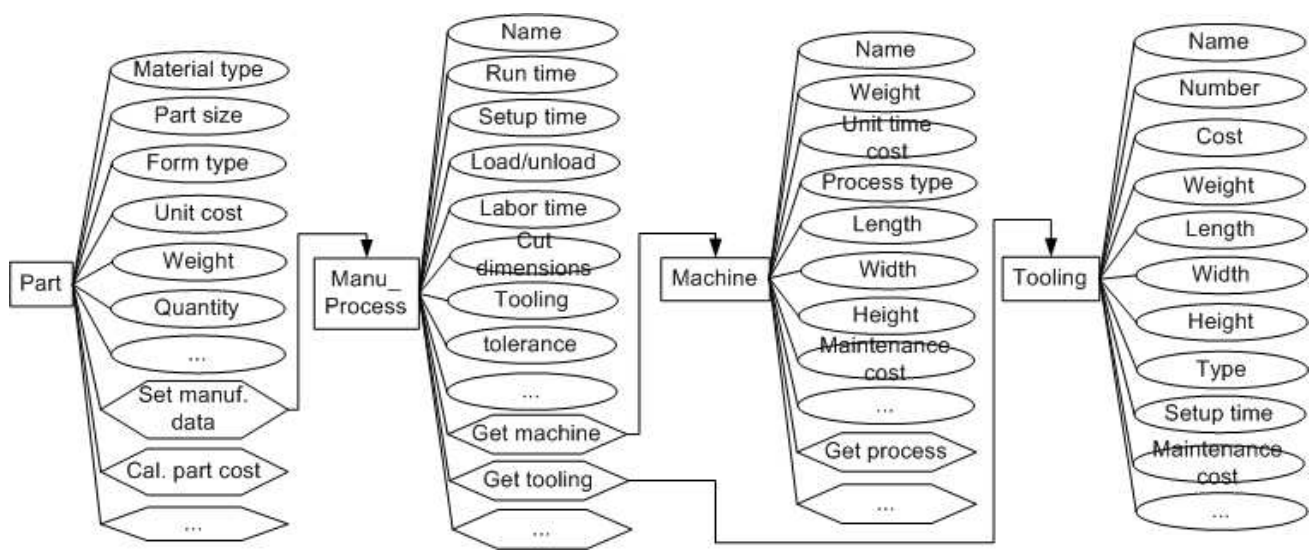

Required objects and associated attributes for part costing $200 \times 82 \mathrm{~mm}(96 \times 96 \mathrm{DPI})$ 


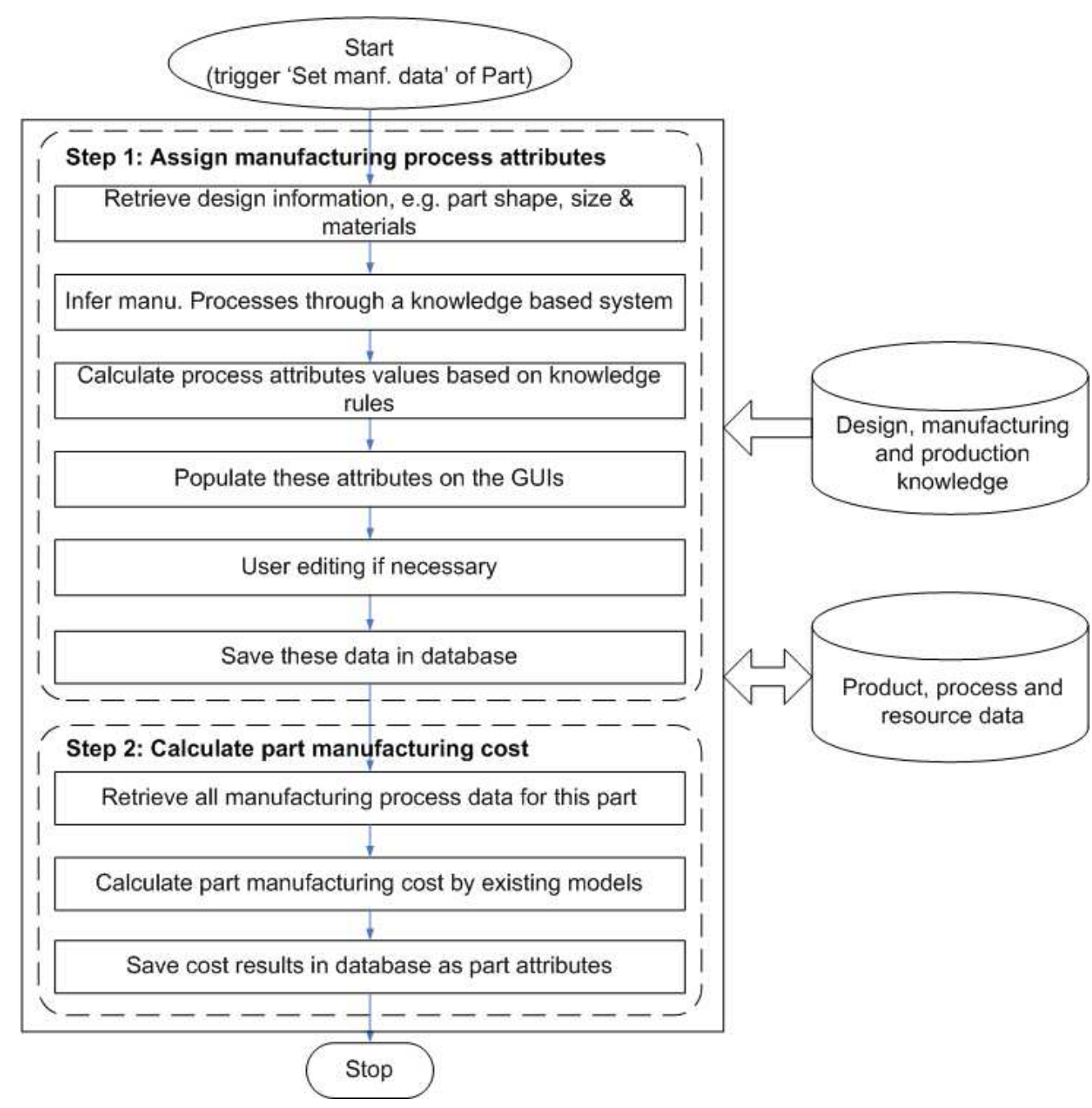

Intelligent prediction of part manufacturing cost $193 \times 195 \mathrm{~mm}(96 \times 96 \mathrm{DPI})$ 


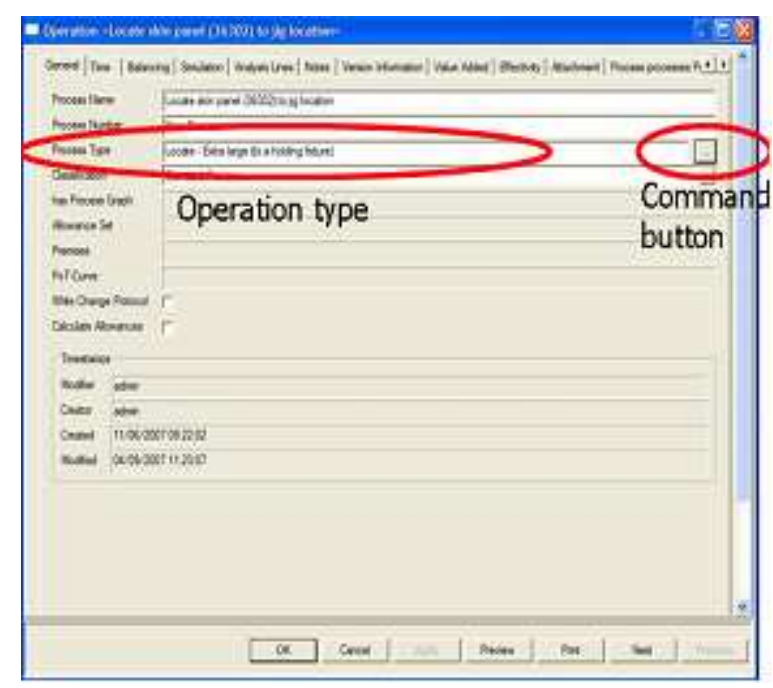

Customized GUI of Operation object $76 \times 67 \mathrm{~mm}$ (96 x $96 \mathrm{DPI})$ 


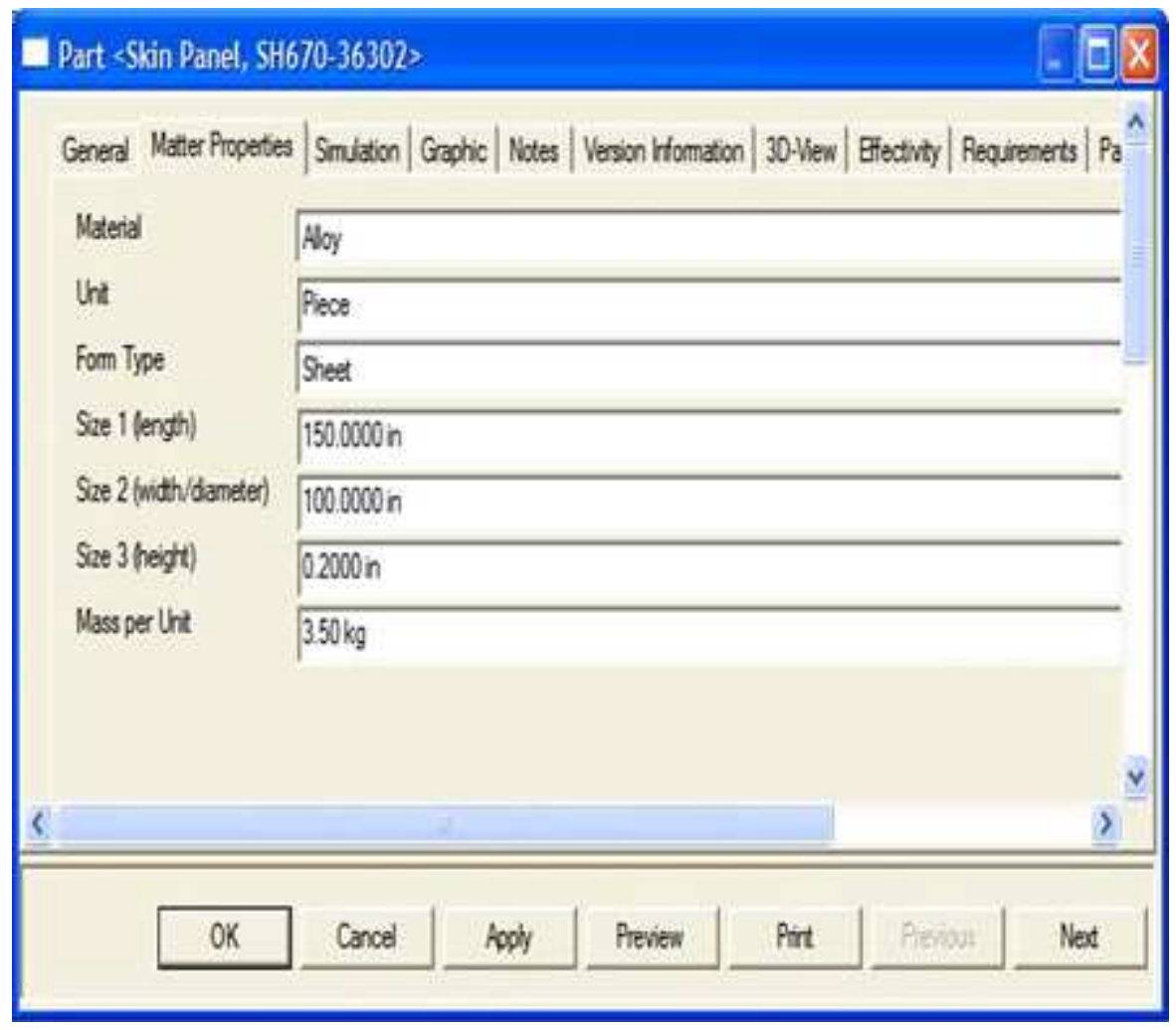

Customized GUI of Part object $118 \times 103 \mathrm{~mm}$ (96 × 96 DPI) 


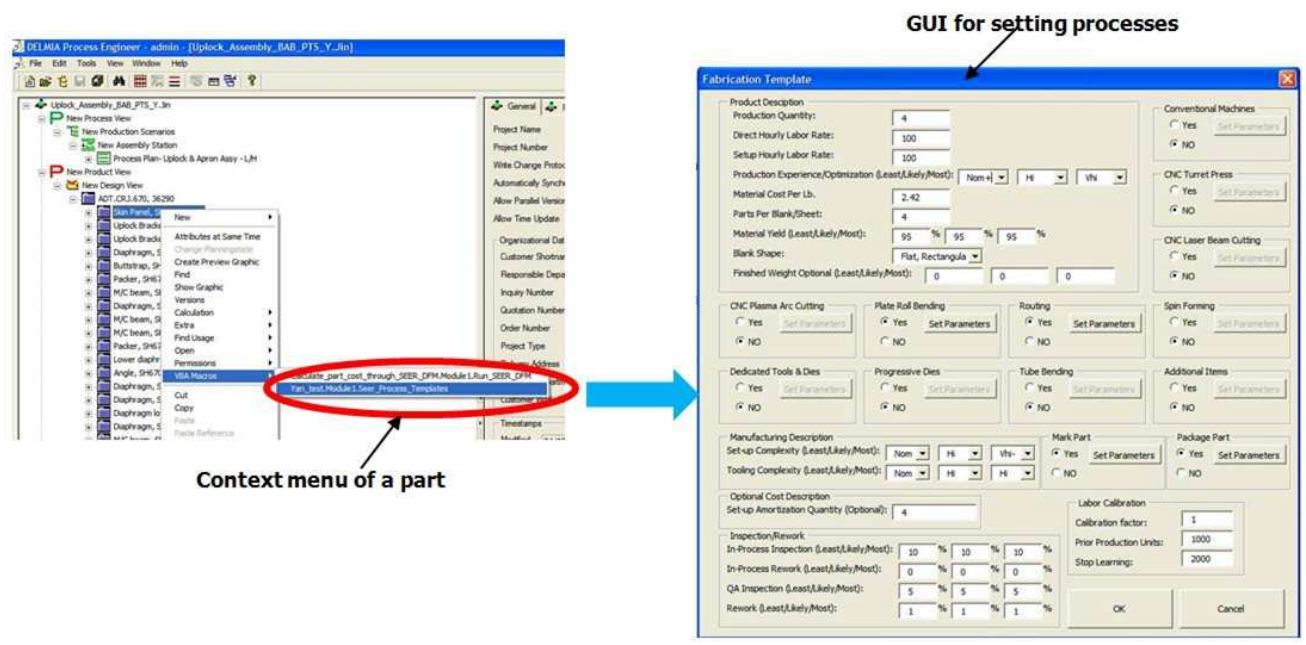

Graphical user interfaces for part costing $288 \times 140 \mathrm{~mm}(96 \times 96 \mathrm{DPI})$ 


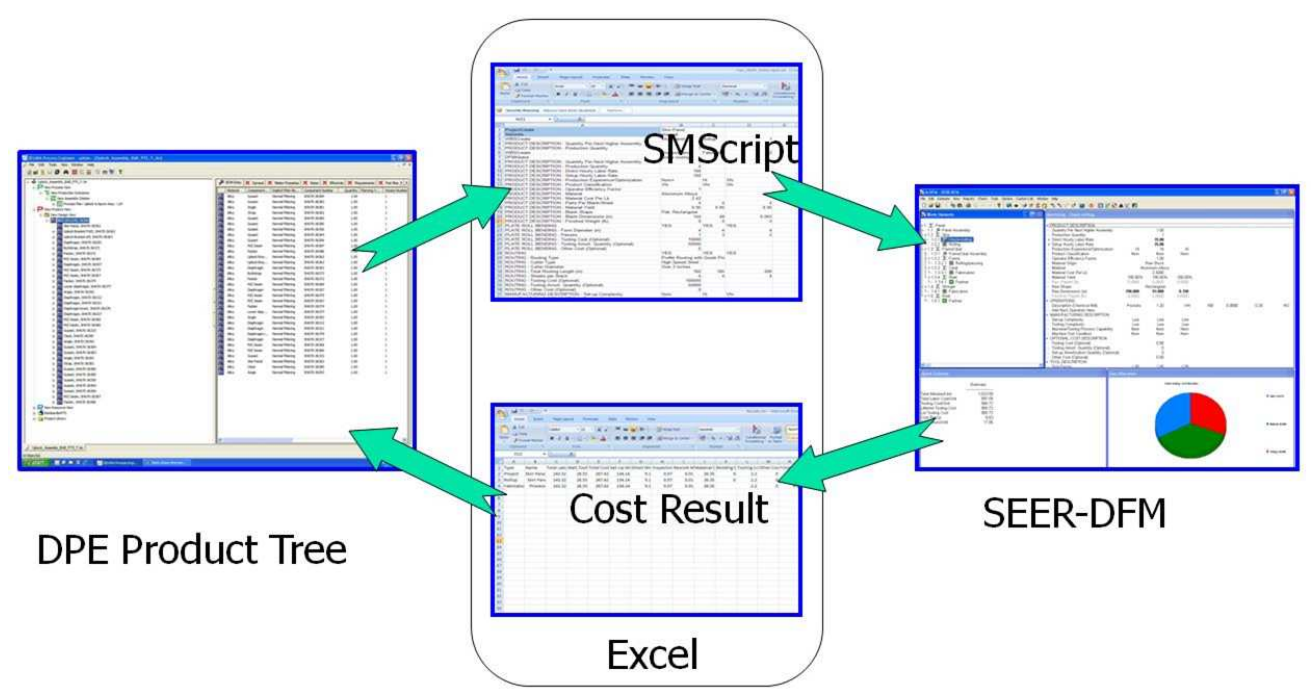

Integration of DPE and SEER-DFM $331 \times 177 \mathrm{~mm}(96 \times 96 \mathrm{DPI})$ 


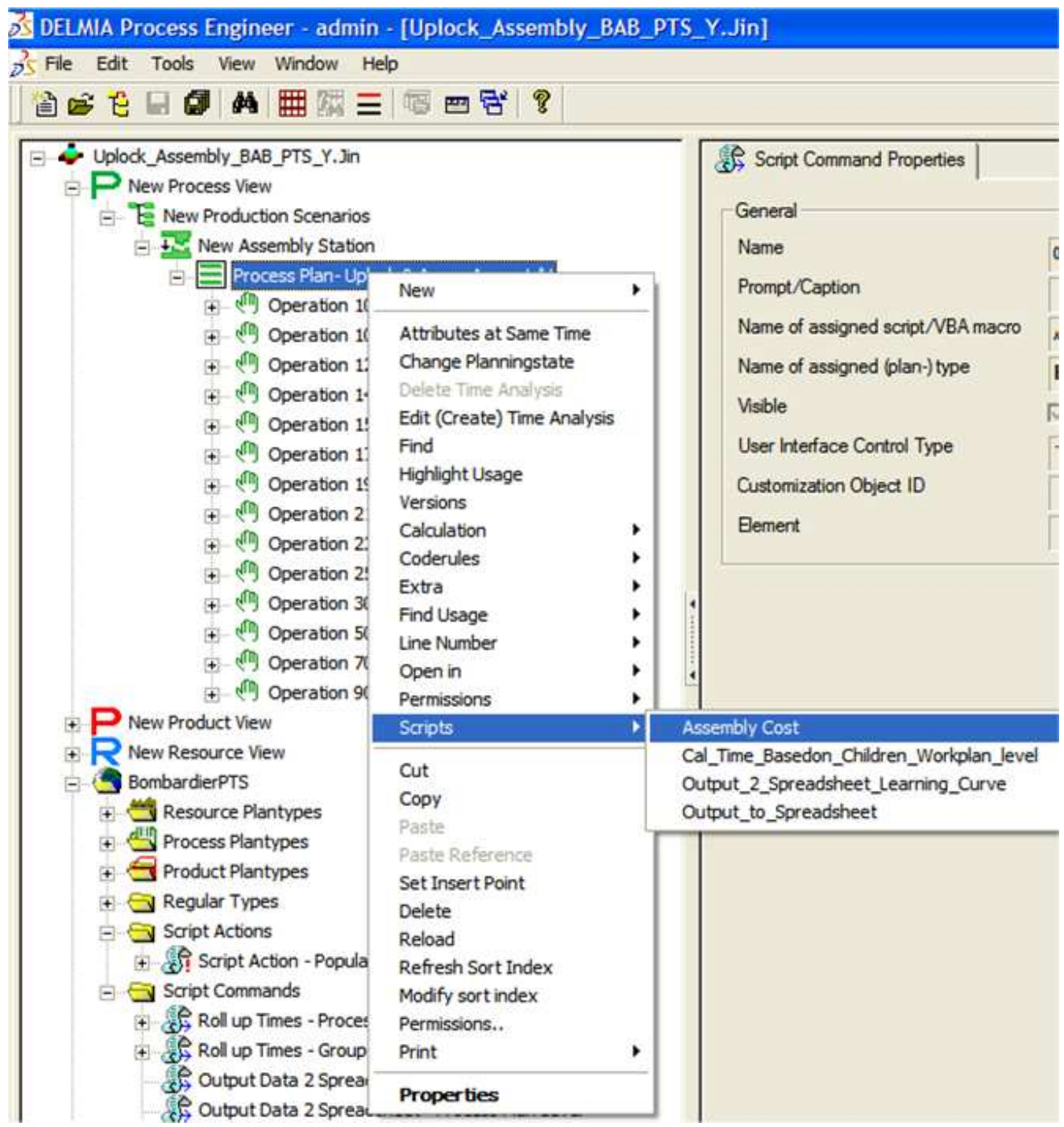

Context menu for calculating assembly cost $176 \times 187 \mathrm{~mm}$ (96 x 96 DPI) 


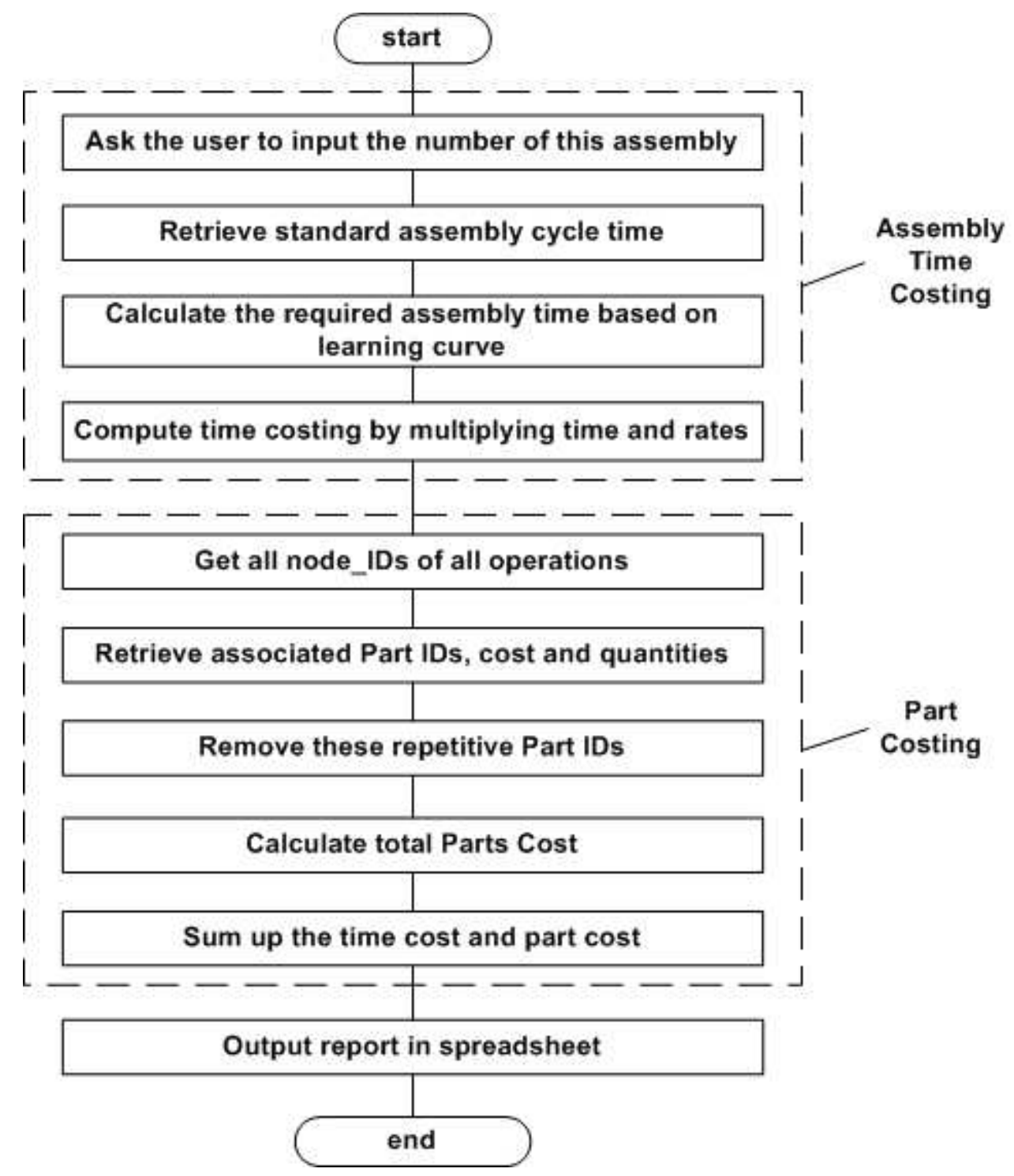

Flowchart for calculating assembly cost $127 \times 148 \mathrm{~mm}(96 \times 96 \mathrm{DPI})$ 


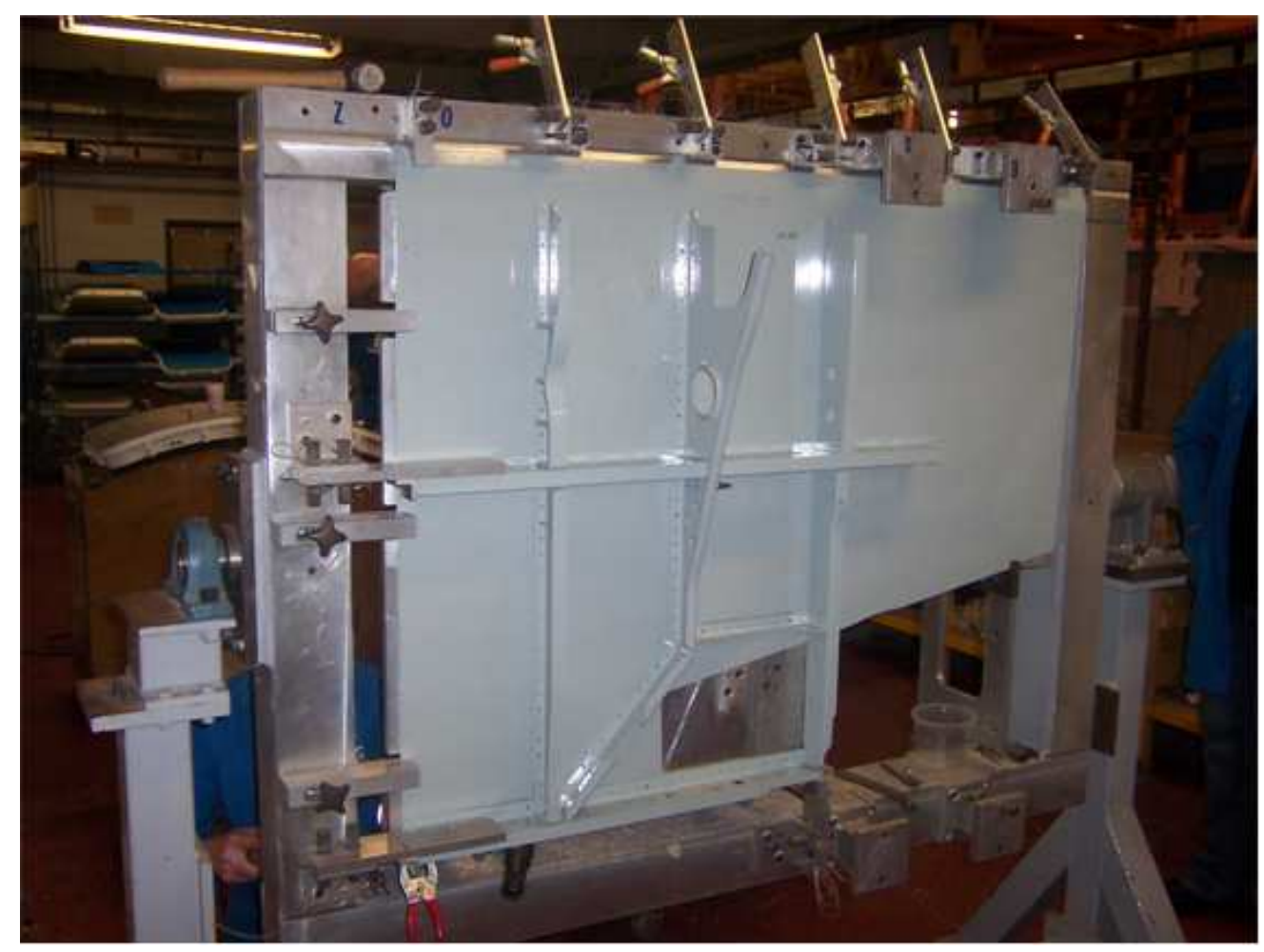

Uplock and Apron Assembly (With Fixture) $150 \times 112 \mathrm{~mm}(96 \times 96 \mathrm{DPI})$ 


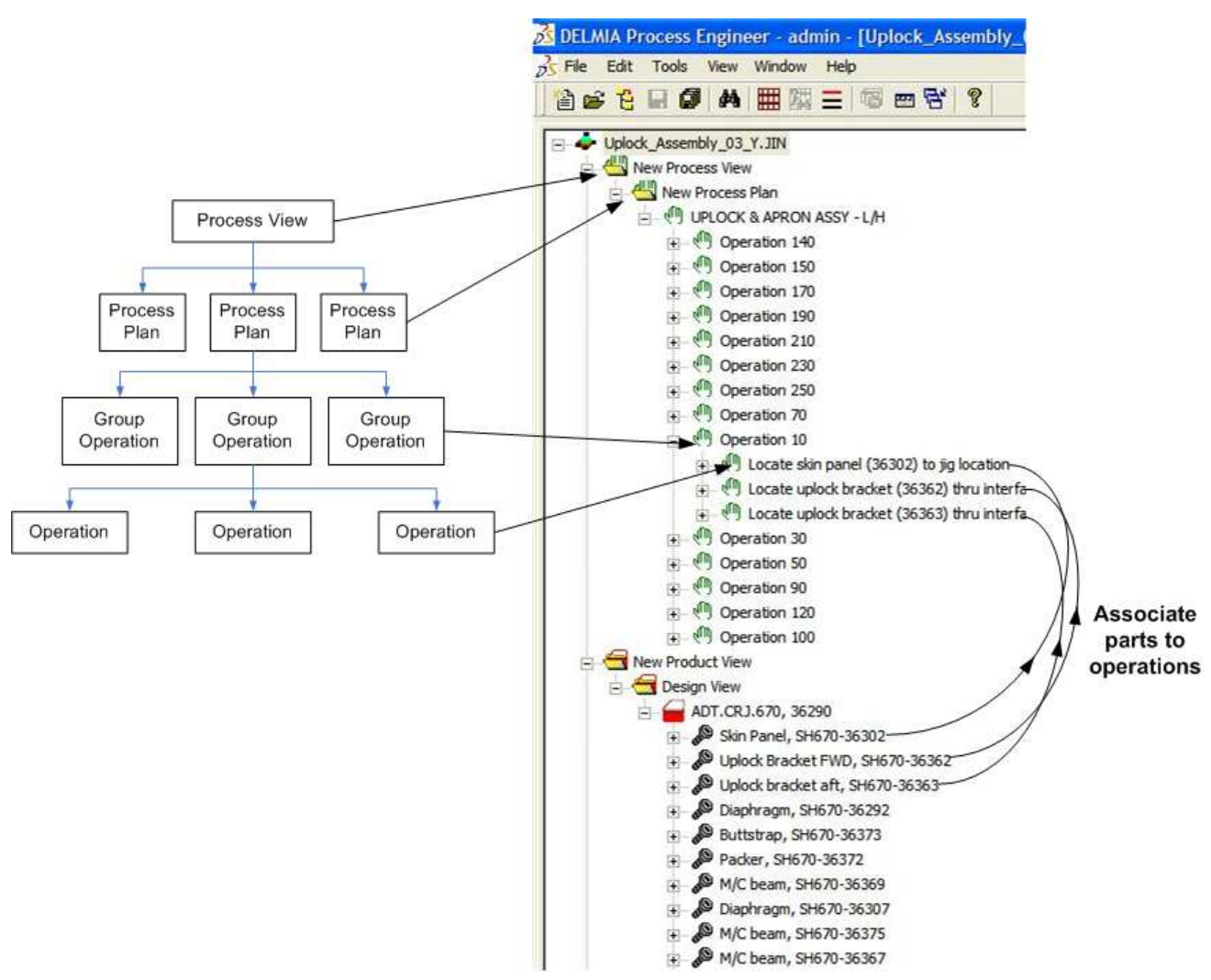

Implementation of the object oriented process structure in DPE $230 \times 183 \mathrm{~mm}(96 \times 96 \mathrm{DPI})$ 


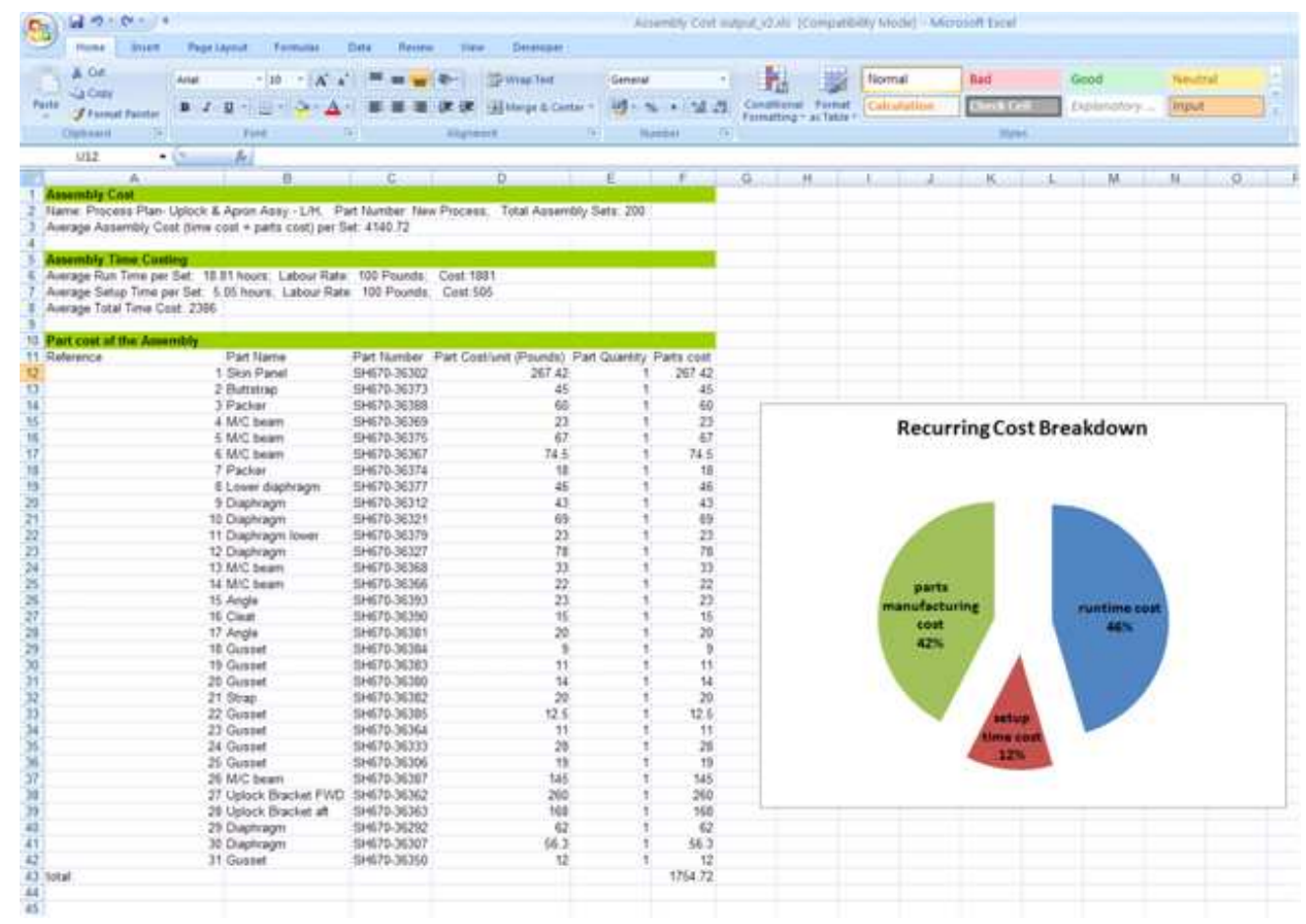

Output report of assembly cost of the Uplock \& Apron Assembly $167 \times 118 \mathrm{~mm}$ ( $96 \times 96$ DPI) 